\title{
ПРОФИЛЬ ЖИРНЫХ КИСЛОТ МЕМБРАН ЭРИТРОЦИТОВ И СЫВОРОТКИ КРОВИ У ПАЦИЕНТОВ С ВОСПАЛИТЕЛЬНЫМИ ЗАБОЛЕВАНИЯМИ КИШЕЧНИКА В ЗАВИСИМОСТИ \\ ОТ СТАДИИ ЗАБОЛЕВАНИЯ
}

FATTY ACID PROFILE OF ERYTHROCYTE MEMBRANES AND BLOOD SERUM IN PATIENTS WITH INFLAMMATORY INTESTINAL DISEASES DEPENDING ON THE STAGE OF THE DISEASE

M. Kruchinina I. Svetlova

A. Azgaldyan M. Osipenko

E. Valuiskikh M. Shashkov

A. Sokolova

V. Kruchinin

I. Yakovina

I. Osipenko

Summary. The aim of this study is to study the characteristics of the fatty acid composition of erythrocyte membranes and blood serum in patients with IBD associated with the stage of the disease, followed by the determination of biomarkers that are significant for determining the activity of IBD.

Materials and methods. We examined 109 patients (mean age $37.7 \pm$ 11.7 years, 59 women, 50 men) with IBD and 53 examined comparison groups (mean age $43.3 \pm 11.7$ years). The group of patients with IBD included patients with ulcerative colitis - 50 people, with Crohn's disease - 41 people and 18 patients with unclassified colitis. 36 patients were examined in dynamics during the year. Taking into account the dynamics, 109 cases of exacerbation of IBD and 36 cases of disease remission were identified. The study of the composition of fatty acids $\mathrm{Er}$ and $\mathrm{SA}$ was carried out using a GC / MS system based on three Agilent 7000B quadrupoles (USA).

Results.. In patients with IBD, an increase in the content of saturated fatty acids (mainly due to palmitic, stearic fatty acids) during the period of exacerbation of the disease compared with healthy individuals was revealed, followed by a decrease in the onset of remission $(p<0.05)$. The total content of unsaturated fatty acids is significantly lower in patients with IBD in the exacerbation stage compared to the control group
Кручинина Маргарита Витальевна

Д.м.н., в.н.с., Научно-исследовательский институт терапии и профилактической медицины - филиал ФГБНУ ФИЦ Институт иитологии и генетики СО РАН; дочент, ФГБОУ ВО «Новосибирский государственный

медицинский университет» Минздрава России kruchmargo@yandex.ru

Светлова Ирина Олеговна

К.м.н., дочент, ФГБОУВО «Новосибирский государственный медицинский университет»

Минздрава России

Азгалдян Александра Викторовна

Аспирант, Научно-исследовательский институт терапии и профилактической медицины - филиал ФГБНУ ФИЦ Институт цитологии и генетики СО РАН communis2016@gmail.com

Осипенко Марина Федоровна

Д.м.н., профессор, ФГБОУ ВО «Новосибирский государственный медицинский университет»

Минздрава России ngma@bk.ru

Валуйских Екатерина Юрьевна

К.м.н., дочент, ФГБОУ ВО «Новосибирский государственный медицинский университет» Минздрава России valuyskich@mail.ru

Шаиков Михаил Вадимович

К.х.н., Н.С., ФГБУН «Институт катализа

им. Г.К. Борескова» СО РАH misha_chem@ngs.ru

Соколова Анастасия Сергеевна

К.х.Н., Н.С., ФГБУН «Новосибирский институт органической химии им. Н.Н. Ворожцова» СО РАН

a.s_sokolova@mail.ru

Кручинин Владимир Николаевич

К.х.Н., С.н.С., ФГБУН «Институт физики полупроводников им. А.В. Ржанова» СО РАН

vladd.kruch@yandex.ru

яковина Ирина Николаевна

К.т.н., доцент, ФГБОУ ВО «Новосибирский государственный технический университет» irina.nir@gmail.com 
(mainly due to monounsaturated, omega-6 polyunsaturated fatty acids) with an increase in the percentage in patients with inactive disease status ( $p<0.0001-0.05$ ). Saturated / unsaturated, saturated / polyunsaturated, omega3 / omega6 PUFA ratios are higher in patients with acute IBD; there was a decrease in the levels of ratios in patients in remission $(p<0.05)$. Revealed inverse correlations of the total content of unsaturated, mono -, polyunsaturated, omega-6 PUFAs with markers of inflammation; associations of the total content of saturated FAs and individual FAs of this class (palmitic, stearic, arachidic) were found to be direct. When analyzing using machine learning and ROC analysis, the key biomarkers for distinguishing patients in the acute stage from healthy individuals were the levels of the following FAs and their ratios: $E$ C18: $2 n-6, E C 14: 0$ / SC14:0, E C17:0, E C20: 0, E C16:1;7 / S C16:1;7, E C20:2n-6 / S C20:2n-6, E C16:1;9 / S C16:1;9, E C18:3n-3 / S C18: 3n-3, E C16:1;9 (AUC0.962, sensitivity 0.939 , specificity 0.888 , diagnostic accuracy 0.919$)$. To differentiate patients in remission from healthy individuals $-E$ C20:0, S C16:2n-6, E C16:1; 9, E C18:0, E total content of saturated fatty acids, E C16: 0, S total content of unsaturated fatty acids, E C18:3n-3 / S C18:3n-3 (AUC0.979, sensitivity 0.956 , specificity 0.962 , diagnostic accuracy 0.961 ). In distinguishing the stages among themselves - E C18:3n-3, S C12:0, S C16: 1;9, E (20:4n-6, E (20:0, E SFA/USFA / S SFA/USFA, E C20:3n-6 / S C20:3n-6, E C16:1; 9, S C22:4n-6, E omega6 / omega3 / S omega6 / omega3, E C18:2n-6 (AUC0.948, sensitivity 0.954, specificity 1.0, diagnostic accuracy 0.962 ).

Conclusion.

Fatty acid levels of erythrocyte membranes and serum are promising for determining the stage of disease in patients with IBD.

Keywords: inflammatory bowel disease, stages, diagnostics, fatty acids, erythrocytes, blood serum.
Осипенко Иван Викторович

Ассистент, ФГБОУВО «Новосибирский государственный технический университет» taur.os.iv@gmail.com

Аннотация. Цель настоящего исследования — изучить особенности состава жирных кислот мембран эритроцитов и сыворотки крови у пациентов C BЗК, ассоциированные со стадией заболевания, с последующим определением биомаркеров, значимых для определения активности ВЗК.

Материалы и методы. Обследовано 109 пациентов (средний возраст 37,7士11,7 года, 59 женщин, 50 мужчин) с В3К и 53 обследуемых группы

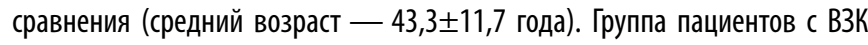
включала в себя больных с язвенным колитом - 50 человек, с болезнью Крона - 41 человек и 18 пациентов с неклассифицированным колитом. 36 пациент обследован в динамике в течение года. С учетом динамики выявлено 109 случаев обострения ВЗК и 36 случаев ремиссии заболеваний.

Исследование состава жирных кислот Эр и СК проведено с помощью ГХ/MC системы на основе трех квадруполей Agilent 7000В (США).

Результаты. У пациентов с ВЗК выявлено увеличение содержания насыщенных ЖК (преимущественно за счет пальмитиновой, стеариновой ЖК) в период обострения заболевания по сравнению со здоровыми лицами с последующим снижением при наступлении ремиссии $(p<0,05)$. Суммарное содержание ненасыщенных ЖК достоверно ниже у пациентов с ВЗК в стадии обострения по сравнению с группой контроля (в большей степени за счет мононенасыщенных, омега-6 полиненасыщенных жирных кислот) с увеличением процентного содержания у пациентов в неактивном статусе заболевания $(p<0,0001-0,05)$. Соотношения насыщенные/ненасыщенные, насыщенные/полиненасыщенные, омега3/омега6 ПНЖК выше у пациентов с ВЗК в стадии обострения; отмечено снижение уровней соотношений у больных в стадии ремиссии $(p<0,05)$. Выявлены обратные корреляции суммарного содержания ненасыщенных, моно -, полиненасыщенных, омега-6 ПНЖК с маркерами воспаления; ассоциации суммарного содержания насыщенных ЖК и отдельных ЖК данного класса (пальмитиновой, стеариновой, арахиновой) оказались прямыми. При проведении анализа методами машинного обучения и ROC-анализа ключевыми биомаркерами для различения пациентов в стадии обострения от здоровых лиц оказались уровни следующих ЖК и их соотношения: E C18:2n-6, E C14:0/ S C14:0, E C17:0, E C20:0, E C16:1;7/ S C16:1;7, E C20:2n-6 / S C20:2n-6, E C16:1;9 / S C16:1;9, Е C18:3n-3 / S C18:3n-3, E C16:1;9 (АUС0,962, чувствительность 0,939, специфичность 0,888, диагностическая точность - 0,919). Для дифференцирования пациентов в стадии ремиссии от здоровых лиц - E (20:0, S C16:2n-6, E C16:1;9, E C18:0, E суммарное содержание насыщенных ЖК, E C16:0, S суммарное содержание ненасыщенных ЖК, Е C18:3n-3 / S C18:3n-3 (AUC0,979, чувствительность 0,956, специфичность 0,962, диагностическая точность - 0,961). В различении стадий между собой - E (18:3n-3, S C12:0, S C16:1;9, E C20:4n-6, E (20:0, E насыщ./ненасыщ./ S насыщ./ненасыщ., E C20:3n-6/S C20:3n-6, E C16:1;9, S C22:4n-6, Е омега 6/омега3 / S омега6/омега3, E C18:2n-6 (АUС0,948, чувствительность 0,954, специфичность 1,0 , диагностическая точность - 0,962). 


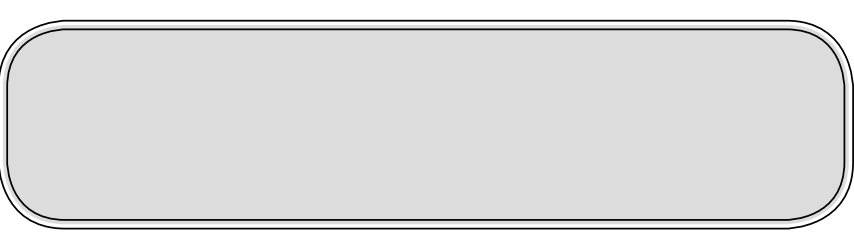

\section{Ввемение}

B оспалительные заболевания кишечника (ВЗК) были и остаются одной из наиболее серьезных проблем в современной гастроэнтерологии. Несмотря на то, что по уровню заболеваемости ВЗК значительно уступают другим гастроэнтерологическим патологиям, по тяжести течения, частоте осложнений и летальности во всем мире они занимают одно из ведущих мест в структуре болезней желудочно-кишечного тракта [1].

При верификации диагноза ВЗК одной из важных рубрик является тяжесть настоящей атаки заболевания, которая соответствует понятию «активность» в зарубежной практике [2]. Все системы оценки тяжести атаки называются индексами активности. Термины «клиническая активность» и «тяжесть обострения» эквивалентны, неактивный процесс соответствует ремиссии заболевания. Данный аспект является весьма важным, поскольку он определяет тактику лечения пациента.

Понятия «обострение» и «ремиссия» у пациентов с ВЗК предполагает детализацию, касающуюся клинических, эндоскопических и гистологических проявлений. В отношении язвенного колита, который определяют как хроническое заболевание толстой кишки, характеризующееся иммунным воспалением ее слизистой оболочки [3], обострение (рецидив, атака) ЯК описывается как появление типичных симптомов заболевания у больных ЯК в стадии клинической ремиссии, спонтанной или медикаментозно поддерживаемой.

Определение болезни Крона (БК) постулирует, что это хроническое, рецидивирующее заболевание желудочно-кишечного тракта (ЖКТ) неясной этиологии, характеризующееся трансмуральным, сегментарным, гранулематозным воспалением с развитием местных и системных осложнений [4]. В отношении обострения БК эксперты повторяют вышеописанное положение, относящееся к ЯК.

На практике признаками клинического обострения ЯК являются увеличение частоты дефекаций с выделением крови и/или характерные изменения, обнаруживаемые при эндоскопическом исследовании толстой кишки.

Ремиссия ЯК - исчезновение основных клинических симптомов заболевания [5] и заживление слизистой обо-
Заключение. Уровни жирных кислот мембран эритроцитов и сыворотки крови перспективны для определения стадии заболевания у пациентов с ВЗК.

Ключевые слова: воспалительные заболевания кишечника, стадии, диагностики, жирные кислоты, эритроциты, сыворотка крови.

лочки толстой кишки («глубокая ремиссия») [6]. Клиническая ремиссия ЯК: отсутствие примеси крови в стуле, отсутствие императивных/ложных позывов при частоте дефекаций не более 3 раз в сутки. Эндоскопическая ремиссия ЯК: отсутствие видимых макроскопических признаков воспаления при эндоскопическом исследовании толстой кишки. Гистологическая ремиссия ЯК: отсутствие микроскопических признаков воспаления.

В отношении БК ремиссия определяется как исчезновение типичных проявлений заболевания [4]. Клиническая ремиссия БК: отсутствие симптомов БК (соответствует значению Индекса активности БК (ИАБК) <150) [7]. Эндоскопическая ремиссия БК [7] соответствует значению упрощенного эндоскопического индекса тяжести БK $($ SES CD) $\leq 3$.

Для определения тяжести атаки при ЯК используют критерии Truelove-Witts [8], индекс активности ЯК (индекс клиники Мейо) [3], которые предполагают необходимость проведения ряда исследований - физикального, исследования показателей красной крови, эндоскопического, являющегося инвазивным (с возможными осложнениями) и предполагающего подготовку пациента, потребность в специальной аппаратуре, специально обученных специалистах. Парциальный индекс (или неполная шкала Мейо) без данных эндоскопии, несколько снижает объективную оценку состояния пациента.

Используемая в индексе Мейо шкала оценки состояния слизистой оболочки по Schroeder [9] предполагает выполнение колоноскопии, которая является «золотым стандартом» в оценке эндоскопической активности, но вместе с тем - дорогостоящей инвазивной процедурой, ассоциированной с риском развития ряда осложнений (кровотечение, повреждение слизистой, перфорация кишки и др.).

Исследование гистологической активности по шкале Гебса (2000) [10] является важным аспектом в оценке статуса при ВЗК, поскольку целью терапии при данной патологии является достижение гистологической ремиссии. Однако, определение ее предполагает необходимость в специальном оборудовании, реактивах, обученных специалистах.

Для определения тяжести текущего обострения при болезни Крона используются критерии, разработан- 
ные Обществом по изучению В3К [11], предполагающие оценку клинических проявлений и ряда маркеров воспаления [10]; индекс Харви-Брэдшоу [12], состоящий только из клинических параметров. Данные параметры доступны в рутинной клинической практике, что обеспечивает возможность оценки тяжести обострения любым специалистом. Вместе с тем, перечень параметров, входящих в тест, обширен, но не содержит оценки эндоскопической картины заболевания, определяя ограничения данного индекса.

Существует также индекс активности болезни Крона (ИАБК, индекс Беста [13]; CDAI), в соответствии с которым выделяют легкую, среднетяжелую и тяжелую активную БК. При его подсчете оценивается ряд клинических аспектов, данные объективного обследования, прием антидиарейных препаратов, а также уровень гематокрита и показатели массы тела. Расчет данного индекса достаточно трудоемок, его валидация варьировала, при подсчете баллов не принимались во внимание субъективная оценка качества жизни, эндоскопические факторы или системные характеристики, такие как утомляемость.

Индекс эндоскопической активности БК (CDEIS) [14] оценивается отдельно, он предполагает детализацию картины поражения (наличие глубоких и поверхностных изъязвлений, протяженность поражения, в том числе, с язвенными дефектами), которая затем ранжируется по баллам. Данный индекс позволяет оценить лишь эндоскопическую картину, не учитывая клинических, биохимических данных.

В Проекте Клинических рекомендаций по диагностике и лечению болезни Крона у взрослых (2020) [15] подчеркивается, что однозначных диагностических критериев БК не существует, диагноз выставляется на основании сочетания данных анамнеза, клинической картины и типичных эндоскопических и гистологических изменений.

Несмотря на масштабные попытки исследований пациентов с ВЗК проведение ранней диагностики по-прежнему является сложной задачей, отсутствуют биомаркеры для быстрого и точного дифференцирования пациентов ВЗК с точки зрения, статуса заболевания (активный и неактивный) и нозологических форм (болезнь Крона и НЯК) [2].

Следует заметить, что различные виды активности - клиническая, биохимическая, эндоскопическая, гистологическая могут не соответствовать друг другу, что вызывает затруднения в оценке статуса конкретного пациента [16].

Несмотря на предпринимаемые попытки исследований хронических воспалительных заболеваний кишеч- ника, патогенез ВЗК по многим аспектам остается не ясным. В процессе решения этих вопросов пристальное внимание приковано к метаболомике, демонстрирующей многообещающие результаты [17]. Представлены результаты метаболомического профилирования, основанного на спектроскопии ядерного магнитного резонанса (ЯМР), которое было выполнено на ряде биологических образцов у пациентов с В3К, включая сыворотку крови [18], мочу [19] и кал [20]. Однако, эти исследования столкнулись с расчётными ограничениями, такими как низкая чувствительность и низкая скорость расшифровки соединений. В то же время, газовая хроматография с масс-спектрометрией (МС) является чувствительной, специфичной и универсальной платформой для получения широкого спектра соединений с высокой пропускной способностью [21]. Поскольку МС продолжает развиваться, некоторые метаболомические исследования (таргетные и нетаргетные), основанные на методе MC, позволили получить новые результаты, значимые в исследованиях ВЗК. Так, недавнее исследование метаболитов в группе пациентов - детей с болезнью Крона и ЯК выявило метаболические особенности в сыворотке крови и кале, которые могут помочь в дифференцировании болезни Крона от ЯК у подростков [22]. В другой работе использовано таргетное профилирование сыворотки крови, в ходе которого определены метаболиты липидного обмена и метаболизма аминокислот, отвечающие критериям ключевых биомаркеров для различения болезни Крона и ЯК [23]. Тем не менее, некоторые результаты являются спорными и требуют подтверждения, а также расширенного обсуждения с точки зрения возможных патогенетических механизмов.

\section{Цель настояшего исслеАования}

Изучить особенности состава жирных кислот мембран эритроцитов и сыворотки крови у пациентов с ВЗК, ассоциированные со стадией заболевания, с последующим определением биомаркеров, значимых для определения активности ВЗК.

Гипотеза настоящего исследования состоит в том, что жирнокислотные профили позволяют не только различать больных с ВЗК и здоровых обследуемых, но и выявлять особенности метаболизма жирных кислот между активными и неактивными состояниями.

\section{Материалы и метолы}

Обследовано 109 пациентов (средний возраст $37,7 \pm 11,7$ года, 59 женщин, 50 мужчин) с В3К и 53 обследуемых группы сравнения (средний возраст 43,3 11,7 года, 28 женщин, 25 мужчин). Группа пациентов с ВЗК включала в себя больных с язвенным колитом - 50 человек, с болезнью Крона - 41 человек и 18 пациентов 
с неклассифицированным колитом. Диагноз был верифицирован на основании сочетания данных анамнеза, клинической картины и типичных эндоскопических и гистологических изменений $[3,15]$.

Среди пациентов с ВЗК 86 обследуемых находились В состоянии обострения заболевания, 23 - в стадии ремиссии. В последующие 0,5-1 года 36 пациент был обследован в динамике наблюдения, на момент повторного обследования у 23 больных выявлено заболевание в активном статусе, у 13 - в неактивном. Таким образом, в совокупности (первое и второе обследование) удалось провести исследование для 109 случаев обострения ВЗК и 36 случаев ремиссии заболеваний.

Понятия «обострение» и «ремиссия» у пациентов с ВЗК предполагает детализацию, касающуюся клинических, эндоскопических и гистологических проявлений. В настоящей работе проанализированы различные виды активности В3К, а также тяжесть настоящего обострения.

Исследование состава жирных кислот Эр и СК проведено с помощью ГХ/МС системы на основе трех квадруполей Agilent $7000 B$ (США). Концентрации жирных кислот выражали в относительных процентах. Предел обнаружения жирной кислоты 1 мкг на образец. Подробное описание пробоподготовки и процесса исследования состава жирных кислот приведено в работе [24]. Кроме содержания отдельных ЖК, определяли суммарное содержание насыщенных, ненасыщенных, полиненасыщенных, омега-3 ПНЖК, омега-6 ПНЖК, их соотношения.

Статистическая обработка данных выполнена с использованием программ Microsoft Excel, STATISTICA ver.10.0, SPSS ver.23 и $\mathrm{H} 2 \mathrm{O}$ ver.3.32. В ходе предварительного анализа данных определялся характер распределения количественных признаков методом Колмогорова-Смирнова. В случае нормального распределения вычислялось среднее значение (M) и стандартное отклонение (SD). Достоверность различия показателей оценивали по критерию Пирсона (для нормального распределения), в случаях отклонения распределения от нормального использовались непараметрические критерии (U-критерий Манна-Уитни, Краскела-Уоллиса). Величину и значимость корреляции между количественными параметрами оценивались путем вычисления коэффициента корреляции Пирсона (r) с расчетом 95\% доверительного интервала. Во всех процедурах статистического анализа критический уровень значимости нулевой гипотезы (р) принимался равным 0,05. При значениях $\mathrm{p} \leq 0,05$ различия между исследуемыми показателями считали статистически значимыми, при 0,05 < p $\leq 0,1$ - обнаруженными на уровне статистической тен- денции. Для определения степени влияния отдельных параметров на изучаемую величину и поиска диагностических моделей был использован метод градиентного бустинга. Интерпретация полученных моделей была выполнена на основании значений относительной важности признаков [25]. Оценка диагностической точности моделей произведена с помощью ROC-анализа.

Исследование выполнено с одобрения Комитета Биомедицинской Этики Научно-исследовательского института терапии и профилактической медицины - филиала Федерального государственного бюджетного научного учреждения «Федеральный исследовательский центр Институт цитологии и генетики Сибирского отделения Российской академии наук» (17.12.2018, протокол № 120). Все пациенты подписали информированное согласие на участие в исследовании.

\section{Результаты}

Клинико-биохимическая характеристика пациентов с ВЗК и лиц группы сравнения представлены в таблице 1.

Пациенты обследованных групп больных с ВЗК в стадии обострения и в ремиссии оказались сопоставимы по возрасту, полу, индексу массы тела, статусу курения, стажу, тяжести, характеру течения заболевания, протяженности процесса. Вместе с тем, среди пациентов в стадии ремиссии оказалась большей доля больных с НКК. По доле пациентов с ЯК и БК в группах с обострением и ремиссией значимых различий не было.

В соответствие с положениями Клинических рекомендаций $[3,15]$, в настоящем исследовании у пациентов с ВЗК в стадии ремиссии отсутствовали или были минимально выражены клинические проявления (индекс Мейо не превышал 2 баллов, индекс активности болезни Крона был менее 150 баллов). У пациентов с ЯК, НКК при эндоскопическом исследовании отсутствовали видимые макроскопические признаки воспаления в толстой кишке, у больных с БК индекс эндоскопической активности БК (CDEIS) не превышал 3 баллов.

В группе пациентов с ВЗК в стадии обострения у 35 (32,1\%) больных отмечена минимальная клиническая активность, у 66 (60,6\%) - умеренная, в 8 случаях (7,3\%) она оказалась высокой. Эндоскопическая активность у 14 пациентов (12,8\%) была минимальной, у 70 (64,2\%)умеренной, у 25 (22,9\%) высокой.

В группе больных ЯК и НКК при оценке тяжести настоящей атаки согласно индексу активности Мейо у 31 пациента (28,4\%) сумма баллов находилась в пределах 3-5 баллов, что соответствовало легкой атаке; у большей части больных - 38 (34,9\%) индекс находился в преде- 
Таблица 1. Клинико-биохимическая характеристика пациентов с ВЗК в стадии обострения и ремиссии и обследуемых группы сравнения (M+SD).

\begin{tabular}{|c|c|c|c|c|}
\hline Показатели & $\begin{array}{l}\text { Группа сравнения, } \\
\mathrm{n}=53 \text { (1) }\end{array}$ & $\begin{array}{l}\text { Группа пациентов } \\
\text { с ВЗК в стадии } \\
\text { обостре-ния } \\
\text { n=109 (2) }\end{array}$ & $\begin{array}{l}\text { Группа пациентов } \\
\text { с ВЗК в стадии } \\
\text { ремиссии } \\
\mathrm{n}=36 \text { (3) }\end{array}$ & p \\
\hline Возраст (лет) & $\begin{array}{l}43,3 \\
\pm 11,7\end{array}$ & $\begin{array}{l}38,2 \\
\pm 12,3\end{array}$ & $\begin{array}{l}36,3 \\
\pm 9,7 \\
\end{array}$ & $>0,1$ \\
\hline Пол (мужчины/женщины) & $25 / 28$ & $51 / 58$ & $16 / 20$ & $>0,1$ \\
\hline Курение, чел. (\%) & $4(7,5)$ & $11(10,1)$ & $4(11,1)$ & $>0,1$ \\
\hline Индекс массы тела (кг/м²) & $21,9 \pm 2,4$ & $20,7 \pm 4,5$ & $22,6 \pm 3,5$ & $>0,1$ \\
\hline Длительность заболевания (годы) & - & $6,23 \pm 5,34$ & $5,4 \pm 4,57$ & $>0,1$ \\
\hline \begin{tabular}{ll}
\multicolumn{2}{l}{ Нозологическая форма ВЗК } \\
$\cdot$ & ЯК \\
$\cdot$ & БК \\
$\cdot$ & НКК \\
\end{tabular} & - & \begin{tabular}{|l|}
$60(55 \%)$ \\
$39(35,8 \%)$ \\
$10(9,2 \%)$ \\
\end{tabular} & \begin{tabular}{|l|}
$15(41,7 \%)$ \\
$10(27,8 \%)$ \\
$11(30,5 \%)^{*}$ \\
\end{tabular} & 0,05 \\
\hline $\begin{array}{l}\text { Степень тяжести течения заболевания } \\
\text { • } \\
\text { • } \\
\text { • } \\
\text { срегкая } \\
\quad \text { тяжелая } \\
\end{array}$ & - & $\begin{array}{l}27(24,8 \%) \\
67(61,5 \%) \\
15(13,8 \%) \\
\end{array}$ & $\begin{array}{l}9(25 \%) \\
22(61,1 \%) \\
5(13,9 \%) \\
\end{array}$ & $>0,1$ \\
\hline 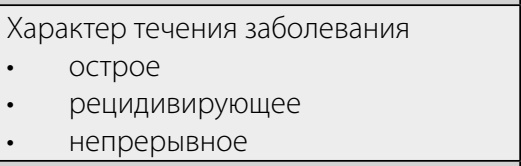 & - & $\begin{array}{l}9(8,3 \%) \\
88(80,7 \%) \\
12(11 \%) \\
\end{array}$ & $\begin{array}{l}3(8,3 \%) \\
33(91,7 \%) \\
-\end{array}$ & $>0,1$ \\
\hline 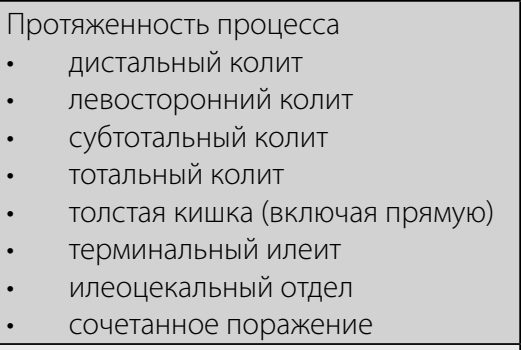 & - & $\begin{array}{l}28(25,7 \%) \\
23(21,1 \%) \\
4(3,7 \%) \\
15(13,8 \%) \\
22(20,2 \%) \\
9(8,3 \%) \\
4(3,7 \%) \\
4(3,7 \%) \\
\end{array}$ & $\begin{array}{l}9(25 \%) \\
8(22,2 \%) \\
2(5,6 \%) \\
7(19,4 \%) \\
6(16,7 \%) \\
2(5,6 \%) \\
2(5,6 \%) \\
- \\
\end{array}$ & $>0,1$ \\
\hline $\begin{array}{l}\text { Стероидозависимость } \\
\text { Стероидорезистентность } \\
\end{array}$ & & \begin{tabular}{|l|}
$25(22,9 \%)$ \\
$3(2,7 \%)$ \\
\end{tabular} & $\begin{array}{l}4(11,1 \%) \\
-\end{array}$ & 0,05 \\
\hline $\begin{array}{l}\text { Анемия } \\
\text { • } \quad \text { железодефицитная } \\
\text { • } \quad \text { анемия воспалительных } \\
\text { заболеваний } \\
\text { · } \quad \text { анемия смешанного генеза }\end{array}$ & - & $\begin{array}{l}36(33 \%) \\
27(24,7 \%) \\
11(10,1 \%)\end{array}$ & $\begin{array}{l}8(22 \%) \\
6(16,7 \%) \\
3(8,3 \%)\end{array}$ & $>0,1$ \\
\hline \begin{tabular}{ll}
\multicolumn{2}{l}{ Терапия } \\
$\cdot$ & аминосалицилаты \\
$\cdot$ & иммуномодуляторы \\
$\cdot$ & кортикостероиды \\
\end{tabular} & - & $\begin{array}{l}88(80,7 \%) \\
42(38,5 \%) \\
57(52,3 \%) \\
\end{array}$ & \begin{tabular}{|l}
$34(94,4 \%)$ \\
- \\
-
\end{tabular} & 0,05 \\
\hline Количество эритроцитов, х1012/л & $\begin{array}{l}4,62 \\
\pm 0,38\end{array}$ & $\begin{array}{l}4,14 \\
\pm 0,61\end{array}$ & $\begin{array}{l}4,44 \\
\pm 0,47\end{array}$ & $\begin{array}{l}p 1-20,0002 \\
p 1-30,003 \\
p 2-30,001\end{array}$ \\
\hline Уровень гемоглобина, г/л & $\begin{array}{l}141,17 \\
\pm 8,73\end{array}$ & $\begin{array}{l}119,59 \\
\pm 19,90\end{array}$ & $\begin{array}{l}133,92 \\
\pm 13,93\end{array}$ & $\begin{array}{l}p 1-20,00001 \\
p 1-30,003 \\
p 2-30,008\end{array}$ \\
\hline $\mathrm{CO}, \mathrm{Mm} / 4$ & \begin{tabular}{|l|}
8,85 \\
$\pm 3,96$ \\
\end{tabular} & \begin{tabular}{|l|}
23,63 \\
$\pm 10,07$ \\
\end{tabular} & \begin{tabular}{|l|}
9,67 \\
$\pm 5,02$ \\
\end{tabular} & $\begin{array}{l}p 1-20,00001 \\
p 2-30,00001 \\
\end{array}$ \\
\hline Количество лейкоцитов, х109/л & $\begin{array}{l}5,94 \cdot 10^{-6} \\
\pm 1,42 \cdot 10^{-6}\end{array}$ & $\begin{array}{l}7,58 \cdot 10^{-6} \\
\pm 2,75 \cdot 10^{-6}\end{array}$ & $\begin{array}{l}5,61 \cdot 10^{-6} \\
\pm 2,13 \cdot 10^{-6}\end{array}$ & $\begin{array}{l}p 1-20,00008 \\
p 1-30,07 \\
p 2-30,00006\end{array}$ \\
\hline С-реактивный белок, мг/л & $\begin{array}{l}2,33 \\
\pm 0,86\end{array}$ & $\begin{array}{l}13,69 \\
\pm 16,41\end{array}$ & $\begin{array}{l}2,28 \\
\pm 1,71\end{array}$ & $\begin{array}{l}\text { p1-2 0,00001 } \\
\text { p1-3 0,08 } \\
\text { p2-3 } 0,00001\end{array}$ \\
\hline
\end{tabular}


Таблица 1 (продолжение). Клинико-биохимическая характеристика пациентов с ВЗК в стадии обострения и ремиссии и обследуемых группы сравнения (M+SD).

\begin{tabular}{|c|c|c|c|c|}
\hline Показатели & $\begin{array}{l}\text { Группа сравнения, } \\
\mathrm{n=53} \text { (1) }\end{array}$ & $\begin{array}{l}\text { Группа пациентов } \\
\text { с ВЗК в стадии } \\
\text { обостре-ния } \\
\text { n=109 (2) }\end{array}$ & $\begin{array}{l}\text { Группа пациентов } \\
\text { с ВЗК в стадии } \\
\text { ремиссии } \\
\text { n=36 (3) }\end{array}$ & p \\
\hline Фибриноген, г/л & $\begin{array}{l}2,57 \\
\pm 0,56\end{array}$ & $\begin{array}{l}5,28 \\
\pm 1,75\end{array}$ & $\begin{array}{l}3,29 \\
\pm 0,71\end{array}$ & $\begin{array}{l}\text { p1-2 0,00001 } \\
\text { p1-3 0,04 } \\
\text { p2-3 0,00001 }\end{array}$ \\
\hline Фекальный кальпротектин, мкг/г & $\begin{array}{l}23,87 \\
\pm 10,6\end{array}$ & $\begin{array}{l}408,63 \\
\pm 163,8\end{array}$ & $\begin{array}{l}46,44 \\
\pm 30,37\end{array}$ & $\begin{array}{l}p 1-20,00001 \\
\text { p1-3 0,07 } \\
\text { p2-3 0,00001 }\end{array}$ \\
\hline
\end{tabular}

Таблица 2. Уровни жирных кислот в мембранах эритроцитов (верхняя строка) и сыворотке крови (нижняя строка, наклонный шрифт) у пациентов ВЗК разной активности и у лиц группы сравнения

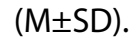

\begin{tabular}{|c|c|c|c|c|c|}
\hline $\begin{array}{l}\text { Содержание жирных кислот } \\
\text { (\%) }\end{array}$ & $\begin{array}{l}\text { Группа } \\
\text { сравнения, } \\
\mathbf{n = 5 3} \\
(1)\end{array}$ & $\begin{array}{l}\text { Группа больных } \\
\text { с В3К в стадии } \\
\text { обострения } \\
\text { n=109 } \\
(2)\end{array}$ & $\begin{array}{l}\text { Группа больных } \\
\text { с В3К в стадии } \\
\text { ремиссии, } \\
\text { n=36 } \\
\text { (3) }\end{array}$ & $\begin{array}{l}\text { Критерий } \\
\text { Манна-Уитни } \\
\text { p }\end{array}$ & $\begin{array}{l}\text { Критерий } \\
\text { Краскела- } \\
\text { Уоллеса }\end{array}$ \\
\hline \multirow{2}{*}{$\begin{array}{l}\text { С12:0 } \\
\text { Додекановая (Лауриновая) }\end{array}$} & $0,51 \pm 0,64$ & $0,23 \pm 0,41$ & $0,27 \pm 0,40$ & $\begin{array}{l}\mathrm{p} 1-2=0,018 \\
\mathrm{p} 1-3=0,013\end{array}$ & 0,0164 \\
\hline & $0,29 \pm 0,30$ & $0,17 \pm 0,23$ & $0,12 \pm 0,14$ & $\begin{array}{l}p 1-2=0,026 \\
p 1-3=0,0017\end{array}$ & 0,0053 \\
\hline \multirow{2}{*}{$\begin{array}{l}\text { C14:0 } \\
\text { Тетрадекановая } \\
\text { (Миристиновая) }\end{array}$} & $1,01 \pm 0,81$ & $0,83 \pm 0,76$ & $0,93 \pm 1,30$ & $p>0,1$ & 0,5180 \\
\hline & $1,45 \pm 0,83$ & $1,00 \pm 0,46$ & $1,14 \pm 0,38$ & $\begin{array}{l}p 1-2=0,0007 \\
p 1-3<0,05\end{array}$ & 0,0022 \\
\hline \multirow{2}{*}{$\begin{array}{l}\text { C15:0 } \\
\text { Пентадекановая }\end{array}$} & $0,38 \pm 0,34$ & $0,30 \pm 0,36$ & $0,28 \pm 0,28$ & $\begin{array}{l}p 1-2=0,026 \\
p 1-3=0,025\end{array}$ & 0,0298 \\
\hline & $0,30 \pm 0,16$ & $0,25 \pm 0,13$ & $0,27 \pm 0,12$ & $p>0,1$ & 0,2471 \\
\hline \multirow{2}{*}{$\begin{array}{l}\text { C16:0 } \\
\text { Гексадекановая } \\
\text { (Пальмитиновая) }\end{array}$} & $29,89 \pm 4,79$ & $32,38 \pm 6,19$ & $30,74 \pm 6,09$ & $p 1-2=0,0109$ & 0,0201 \\
\hline & $25,94 \pm 4,77$ & $28,88 \pm 5,56$ & $26,31 \pm 4,38$ & $\begin{array}{l}p 1-2=0,0012 \\
p 2-3=0,083\end{array}$ & 0,0041 \\
\hline \multirow{2}{*}{$\begin{array}{l}\text { C16:1;7 Цис-7-гексадекановая } \\
\text { (7-Пальмитооле- } \\
\text { иновая) }\end{array}$} & $0,61 \pm 0,55$ & $0,47 \pm 0,76$ & $0,48 \pm 0,76$ & $\begin{array}{l}\mathrm{p} 1-2<0,05 \\
\mathrm{p} 1-3=0,065\end{array}$ & 0,0786 \\
\hline & $0,46 \pm 0,26$ & $0,41 \pm 0,33$ & $0,40 \pm 0,27$ & $p>0,1$ & 0,3677 \\
\hline \multirow{2}{*}{$\begin{array}{l}\text { C16:1;9 Цис-9-гексадекановая } \\
\text { (Пальмитооле-иновая) }\end{array}$} & $1,40 \pm 0,94$ & $0,78 \pm 1,06$ & $0,69 \pm 0,80$ & $\begin{array}{l}\mathrm{p} 1-2<0,0001 \\
\mathrm{p} 1-3<0,0001\end{array}$ & 0,00001 \\
\hline & $1,16 \pm 0,62$ & $0,94 \pm 0,61$ & $0,97 \pm 0,44$ & $p>0,1$ & 0,2435 \\
\hline
\end{tabular}


Таблица 2 (продолжение). Уровни жирных кислот в мембранах эритроцитов (верхняя строка) и сыворотке крови (нижняя строка, наклонный шрифт) у пациентов ВЗК разной активности и у лиц

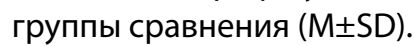

\begin{tabular}{|c|c|c|c|c|c|}
\hline $\begin{array}{l}\text { Содержание жирных кислот } \\
\text { (\%) }\end{array}$ & $\begin{array}{l}\text { Группа } \\
\text { сравнения, } \\
\mathrm{n}=53 \\
(1)\end{array}$ & $\begin{array}{l}\text { Группа больных } \\
\text { с В3К в стадии } \\
\text { обострения } \\
\mathrm{n}=109 \\
(2)\end{array}$ & $\begin{array}{l}\text { Группа больных } \\
\text { с ВЗК в стадии } \\
\text { ремиссии, } \\
\text { n=36 } \\
\text { (3) }\end{array}$ & $\begin{array}{l}\text { Критерий } \\
\text { Манна-Уитни } \\
\text { p }\end{array}$ & $\begin{array}{l}\text { Критерий } \\
\text { Краскела- } \\
\text { Уоллеса }\end{array}$ \\
\hline \multirow{2}{*}{$\begin{array}{l}\text { C17:0 } \\
\text { Гептадекановая } \\
\text { (Маргариновая) }\end{array}$} & $0,35 \pm 0,13$ & $0,30 \pm 0,12$ & $0,33 \pm 0,15$ & $p 1-2=0,005$ & 0,0154 \\
\hline & $0,27 \pm 0,11$ & $0,26 \pm 0,09$ & $0,28 \pm 0,09$ & $p>0,1$ & 0,6795 \\
\hline \multirow{2}{*}{$\begin{array}{l}\mathbf{C 1 6 : 2 ; 9 , 1 2}(\mathbf{n}-\mathbf{6}) \\
\text { Гексадекадиеновая }\end{array}$} & $0,10 \pm 0,11$ & $0,08 \pm 0,11$ & $0,20 \pm 0,61$ & $\begin{array}{l}p 1-3=0,016 \\
p 2-3=0,036\end{array}$ & 0,0479 \\
\hline & $0,10 \pm 0,08$ & $0,07 \pm 0,10$ & $0,11 \pm 0,20$ & $\begin{array}{l}p 1-2=0,019 \\
p 1-3=0,031\end{array}$ & 0,0266 \\
\hline \multirow{2}{*}{$\begin{array}{l}\text { C18:0 } \\
\text { Октадекановая (Стеариновая) }\end{array}$} & $19,65 \pm 8,28$ & $22,94 \pm 7,19$ & $20,82 \pm 5,97$ & $\begin{array}{l}\mathrm{p} 1-2=0,081 \\
\mathrm{p} 1-3=0,047\end{array}$ & 0.1126 \\
\hline & $10,58 \pm 5,21$ & $16,78 \pm 8,45$ & $13,89 \pm 7,28$ & $\begin{array}{l}\mathrm{p} 1-2=0,0005 \\
\mathrm{p} 1-3=0,03\end{array}$ & 0,0018 \\
\hline \multirow{2}{*}{$\begin{array}{l}\text { C18:1; с9 Цис-9-октадекановая } \\
\text { (Олеиновая) }\end{array}$} & $12,88 \pm 3,37$ & $11,18 \pm 3,27$ & $11,91 \pm 2,52$ & $\begin{array}{l}\mathrm{p} 1-2=0,017 \\
\mathrm{p} 1-3=0,05\end{array}$ & 0,0358 \\
\hline & $17,31 \pm 5,08$ & $14,87 \pm 5,35$ & $15,89 \pm 4,78$ & $\begin{array}{l}p 1-2=0,04 \\
p 1-3=0,09\end{array}$ & 0,0897 \\
\hline \multirow{2}{*}{$\begin{array}{l}\text { C18:1; t9 Транс-9- } \\
\text { октадекановая } \\
\text { (Элаидиновая) }\end{array}$} & $1,22 \pm 0,58$ & $1,02 \pm 0,44$ & $0,99 \pm 0,48$ & p1-2=0,044 & 0,1222 \\
\hline & $1,25 \pm 0,56$ & $1,27 \pm 0,70$ & $1,33 \pm 0,65$ & $p>0,1$ & 0,8312 \\
\hline \multirow{2}{*}{$\begin{array}{l}\text { C18:2;9,12 (n-6) } \\
\text { Октадекадиеновая } \\
\text { (Линолевая) }\end{array}$} & $12,72 \pm 3,83$ & $10,22 \pm 3,64$ & $11,73 \pm 3,87$ & $\begin{array}{l}\mathrm{p} 1-2=0,001 \\
\mathrm{p} 1-3=0,053\end{array}$ & 0,0038 \\
\hline & $32,04 \pm 7,79$ & $26,33 \pm 8,01$ & $29,64 \pm 7,22$ & $\begin{array}{l}p 1-2=0,0002 \\
p 2-3=0,09\end{array}$ & 0,0009 \\
\hline \multirow{2}{*}{$\begin{array}{l}\text { С20:0 } \\
\text { (Эйкозановая, Арахиновая) }\end{array}$} & $0,20 \pm 0,18$ & $0,38 \pm 0,26$ & $0,37 \pm 0,26$ & $\begin{array}{l}\text { p1-2 }=0,0023 \\
\text { p1-3 }=0,0002 \\
\text { p2-3 }=0,073\end{array}$ & 0,0003 \\
\hline & $0,17 \pm 0,11$ & $0,28 \pm 0,18$ & $0,27 \pm 0,18$ & $\begin{array}{l}p 1-2=0,007 \\
p 1-3=0,019\end{array}$ & 0,0110 \\
\hline \multirow{2}{*}{$\begin{array}{l}\text { C18:3;6,9,12 (n-3) } \\
\text { Октадекатриеновая } \\
\text { (а-Линоленовая) }\end{array}$} & $0,10 \pm 0,08$ & $0,08 \pm 0,12$ & $0,14 \pm 0,20$ & $\begin{array}{l}\mathrm{p} 1-2=0,023 \\
\mathrm{p} 2-3=0,014\end{array}$ & 0,0135 \\
\hline & $0,24 \pm 0,18$ & $0,12 \pm 0,11$ & $0,19 \pm 0,16$ & $\begin{array}{l}p 1-2=0,0002 \\
p 1-3=0,09\end{array}$ & 0,0013 \\
\hline \multirow{2}{*}{$\begin{array}{l}\text { с20:2;11,14 (n-6) } \\
\text { (Докодиеновая) }\end{array}$} & $0,26 \pm 0,15$ & $0,28 \pm 0,15$ & $0,30 \pm 0,18$ & $p>0,1$ & 0,4395 \\
\hline & $0,16 \pm 0,09$ & $0,15 \pm 0,08$ & $0,19 \pm 0,10$ & $p 2-3=0,07$ & 0,2349 \\
\hline \multirow{2}{*}{ 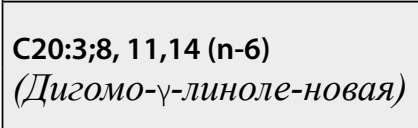 } & $1,09 \pm 0,53$ & $1,00 \pm 0,41$ & $1,10 \pm 0,30$ & $p>0,1$ & 0,5252 \\
\hline & $0,85 \pm 0,36$ & $0,83 \pm 0,40$ & $0,90 \pm 0,33$ & $p>0,1$ & 0,5152 \\
\hline
\end{tabular}

Примечание. Для уровня каждой жирной кислоты представлены величины и достоверность различий в мембранах эритроцитов (верхняя строка) и сыворотке крови (ниюняя строка, наклоннылй ирифт) 
Таблица 2 (продолжение). Уровни жирных кислот в мембранах эритроцитов (верхняя строка) и сыворотке крови (нижняя строка, наклонный шрифт) у пациентов ВЗК разной активности и у лиц

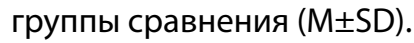

\begin{tabular}{|c|c|c|c|c|c|}
\hline $\begin{array}{l}\text { Содержание жирных кислот } \\
\text { (\%) }\end{array}$ & $\begin{array}{l}\text { Группа } \\
\text { сравнения, } \\
n=53 \\
(1)\end{array}$ & $\begin{array}{l}\text { Группа больных } \\
\text { с В3К в стадии } \\
\text { обострения } \\
n=109 \\
(2)\end{array}$ & $\begin{array}{l}\text { Группа больных } \\
\text { с В3К в стадии } \\
\text { ремиссии, } \\
\text { n=36 } \\
(3)\end{array}$ & $\begin{array}{l}\text { Критерий } \\
\text { Манна-Уитни } \\
\text { p }\end{array}$ & $\begin{array}{l}\text { Критерий } \\
\text { Краскела- } \\
\text { Уоллеса }\end{array}$ \\
\hline \multirow{2}{*}{$\begin{array}{l}\text { С20:4;5,8,11,14 (n-6) } \\
\text { (Эйкозатетраено-вая, } \\
\text { арахидоновая) }\end{array}$} & $10,90 \pm 3,56$ & $10,37 \pm 3,72$ & $11,24 \pm 3,26$ & $p 2-3=0,04$ & 0,1182 \\
\hline & $4,72 \pm 1,84$ & $4,78 \pm 1,60$ & $5,44 \pm 1,71$ & $\begin{array}{l}p 1-3=0,04 \\
p 2-3=0,04\end{array}$ & 0,0951 \\
\hline \multirow{2}{*}{$\begin{array}{l}\text { C20:5;5,8,11,14,17 (n-3) } \\
\text { (Эйкозапентаеновая) }\end{array}$} & $0,50 \pm 0,30$ & $0,54 \pm 0,36$ & $0,59 \pm 0,38$ & $p>0,1$ & 0,5722 \\
\hline & $0,55 \pm 0,84$ & $0,53 \pm 0,50$ & $0,59 \pm 0,46$ & $p>0,1$ & 0,3477 \\
\hline \multirow{2}{*}{$\begin{array}{l}\text { C22:4;7,10,13,16 (n-6) } \\
\text { (Докозатетраено-вая) }\end{array}$} & $2,11 \pm 1,13$ & $2,14 \pm 1,10$ & $2,45 \pm 1,04$ & $\begin{array}{l}p 1-3=0,048 \\
p 2-3=0,022\end{array}$ & 0,0667 \\
\hline & $0,22 \pm 0,20$ & $0,21 \pm 0,18$ & $0,23 \pm 0,25$ & $p>0,1$ & 0,9374 \\
\hline \multirow{2}{*}{ 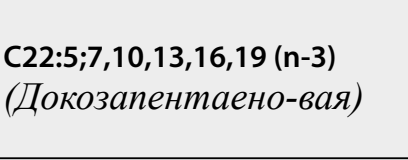 } & $1,29 \pm 0,53$ & $1,41 \pm 0,79$ & $1,42 \pm 0,64$ & $p>0,1$ & 0,5456 \\
\hline & $0,32 \pm 0,28$ & $0,35 \pm 0,23$ & $0,45 \pm 0,32$ & $\begin{array}{l}\mathrm{p} 1-3=0,017 \\
\mathrm{p} 2-3<0,05\end{array}$ & 0,0534 \\
\hline \multirow{2}{*}{$\begin{array}{l}\text { С22:6;4,7,10,13,16,19 (n-3) } \\
\text { (Докозагексаено-вая) }\end{array}$} & $2,63 \pm 1,22$ & $2,96 \pm 1,32$ & $2,94 \pm 1,09$ & $\mathrm{p} 1-3=0,044$ & 0,1553 \\
\hline & $1,19 \pm 0,76$ & $1,57 \pm 0,81$ & $1,38 \pm 0,54$ & $\begin{array}{l}\mathrm{p} 1-2=0,02 \\
\mathrm{p} 1-3=0,03\end{array}$ & 0,0348 \\
\hline
\end{tabular}

лах от 6 до 9 баллов (среднетяжелая атака), у одного пациента (0,92\%) индекс составил 11 баллов, что отражало тяжелую атаку ЯК. У пациентов с болезнью Крона в стадии обострения индекс Беста в среднем равнялся 197,8 \pm 41,7 балла, что соответствовало легкой атаке.

Пациенты в стадии обострения и ремиссии различались по проводимой терапии: в стадии ремиссии большая часть больных принимала препараты 5-аминосалициловой кислоты (34 человека, 94,4\%). В стадии обострения, кроме препаратов 5-АСК, проводилось лечение иммуномодуляторами $(38,5 \%)$ и кортикостероидами (52,3\%) у значительной доли пациентов группы, среди них оказалось больше лиц со стероидозависимостью и стероидорезистентностью $(\mathrm{p}<0,05)$.

Количество эритроцитов и уровень гемоглобина у пациентов с ВЗК как в стадии обострения ( $<<0,00001-$ $0,0002)$, так и в ремиссии ( $p=0,003)$, оказался достоверно ниже, чем у здоровых лиц. При наличии активности ВЗК эти показатели также были достоверно ниже, чем в неактивной стадии ( $p=0,001-0,008)$. Следует заметить, что группы с обострением и ремиссией ВЗК были сопостави- мы по наличию анемий различного генеза - железодефицитной, воспалительных заболеваний и смешанной этиологии.

Уровни ряда маркеров воспаления - количество лейкоцитов, СОЭ, СРБ, фибриноген, фекальный кальпротектин - в группе пациентов с ВЗК в стадии обострения оказались достоверно выше, чем в группе контроля и у пациентов с В3К в стадии ремиссии ( $p=0,00001-0,008)$. Кроме того, и в стадии ремиссии при ВЗК уровень фибриногена оказался выше, чем у здоровых лиц $(p=0,04)$.

Таким образом, две группы пациентов с В3К (в стадии ремиссии и в стадии обострения) имели сопоставимые половозрастные характеристики и особенности течения заболевания (нозологические формы, стаж, тяжесть, характер течения заболевания, протяженность процесса), но различались по степени выраженности клинической, биохимической, эндоскопической активности и по проводимой терапии. У пациентов с В3К в стадии обострения выявлены более высокие уровни маркеров воспаления и большая выраженность анемического синдрома, чем у здоровых лиц и у пациентов в стадии ремиссии. 
Таблица 3. Индексы жирных кислот в мембранах эритроцитов (верхняя строка) и сыворотке крови (нижняя строка, наклонный шрифт) у пациентов ВЗК разной активности и лиц группы сравнения $(\mathrm{M} \pm \mathrm{SD})$.

\begin{tabular}{|c|c|c|c|c|c|}
\hline $\begin{array}{l}\text { Индексы } \\
\text { жирных кислот }\end{array}$ & $\begin{array}{l}\text { Группа } \\
\text { сравнения, } \\
n=53 \\
(1)\end{array}$ & $\begin{array}{l}\text { Группа больных } \\
\text { с ВЗК в стадии } \\
\text { обострения } \\
\mathrm{n}=109 \\
(2)\end{array}$ & $\begin{array}{l}\text { Группа больных с } \\
\text { В3К в стадии } \\
\text { ремиссии, } \\
n=36 \\
(3)\end{array}$ & $\begin{array}{l}\text { Критерий } \\
\text { Манна-Уитни } \\
\text { p }\end{array}$ & $\begin{array}{l}\text { Критерий } \\
\text { Краскела- } \\
\text { Уоллеса }\end{array}$ \\
\hline \multirow{2}{*}{ Насыщенные } & $51,84 \pm 12,18$ & $57,37 \pm 11,63$ & $53,55 \pm 9,40$ & $p 1-2=0,0109$ & 0,0335 \\
\hline & $39,4 \pm 8,93$ & $47,54 \pm 13,28$ & $42,12 \pm 11,31$ & $\mathrm{p} 1-2=0,002$ & 0,0108 \\
\hline \multirow{2}{*}{ Ненасыщенные } & $48,11 \pm 12,14$ & $42,58 \pm 11,61$ & $46,40 \pm 9,30$ & $p 1-2=0,011$ & 0,0338 \\
\hline & $60,6 \pm 8,93$ & $52,44 \pm 13,25$ & $57,88 \pm 11,31$ & $p 1-2=0,002$ & 0,0106 \\
\hline \multirow[t]{2}{*}{ Моно-ненасыщенные } & $16,21 \pm 4,21$ & $13,47 \pm 4,22$ & $14,19 \pm 3,40$ & $\begin{array}{l}\mathrm{p} 1-2=0,006 \\
\mathrm{p} 1-3=0,036\end{array}$ & 0,0144 \\
\hline & $20,08 \pm 5,75$ & $17,55 \pm 6,08$ & $18,57 \pm 5,24$ & $p 1-2=0,07$ & 0,1294 \\
\hline \multirow[b]{2}{*}{ Поли-ненасыщенные } & $31,90 \pm 9,70$ & $29,11 \pm 8,59$ & $32,21 \pm 7,57$ & $p>0,1$ & 0,1831 \\
\hline & $40,42 \pm 8,35$ & $34,90 \pm 9,37$ & $39,32 \pm 7,70$ & $\begin{array}{l}p 1-2=0,0012 \\
\text { p2-3 }=0,06\end{array}$ & 0,0036 \\
\hline \multirow{2}{*}{ Омега-3 } & $4,67 \pm 2,51$ & $5,02 \pm 2,28$ & $5,10 \pm 1,84$ & $p 1-3=0,042$ & 0,1855 \\
\hline & $2,37 \pm 1,74$ & $2,60 \pm 1,33$ & $2,80 \pm 1,60$ & $\mathrm{p} 1-2=0,04$ & 0,1266 \\
\hline \multirow[b]{2}{*}{ Омега-6 } & $27,13 \pm 8,56$ & $24,00 \pm 7,04$ & $26,90 \pm 6,67$ & $\mathrm{p} 1-2<0,05$ & 0,0993 \\
\hline & $37,95 \pm 8,29$ & $32,25 \pm 9,11$ & $36,40 \pm 7,53$ & $\begin{array}{l}p 1-2=0,0008 \\
\text { p2-3 }=0,09\end{array}$ & 0,0030 \\
\hline \multirow{2}{*}{ Омега-3 (EPA+DHA) } & $3,23 \pm 1,48$ & $3,52 \pm 1,60$ & $3,58 \pm 1,39$ & $p 1-3=0,033$ & 0,1209 \\
\hline & $1,82 \pm 1,54$ & $2,13 \pm 1,18$ & $2,16 \pm 1,48$ & $\mathrm{p} 1-3=0,06$ & 0,1333 \\
\hline \multirow[b]{2}{*}{ омега-6/омега-3 } & $6,64 \pm 2,62$ & $5,48 \pm 2,37$ & $5,81 \pm 2,00$ & $\begin{array}{l}p 1-2=0,022 \\
p 1-3<0,05\end{array}$ & 0,0454 \\
\hline & $22,18 \pm 15,49$ & $15,36 \pm 8,46$ & $16,26 \pm 7,80$ & $\begin{array}{l}\mathrm{p} 1-2=0,02 \\
\mathrm{p} 1-3<0,05\end{array}$ & 0,0499 \\
\hline \multirow{2}{*}{$\begin{array}{l}\text { насыщенные./ } \\
\text { ненасыщенные }\end{array}$} & $1,28 \pm 0,88$ & $1,64 \pm 1,27$ & $1,25 \pm 0,48$ & $p 1-2=0,0109$ & 0,0337 \\
\hline & $0,70 \pm 0,36$ & $1,06 \pm 0,62$ & $0,81 \pm 0,45$ & $p 1-2=0,002$ & 0,0114 \\
\hline \multirow{2}{*}{$\begin{array}{l}\text { Насыщенные / } \\
\text { полиненасыщенные }\end{array}$} & $2,03 \pm 1,54$ & $2,46 \pm 2,13$ & $1,48 \pm 0,78$ & $\mathrm{p} 1-2=0,04$ & 0,0997 \\
\hline & $1,07 \pm 0,54$ & $1,59 \pm 0,92$ & $1,19 \pm 0,64$ & $\mathrm{p} 1-2=0,0017$ & 0,0061 \\
\hline \multirow{2}{*}{ омега-3/омега-6 } & $0,17 \pm 0,10$ & $0,21 \pm 0,08$ & $0,19 \pm 0,07$ & $\begin{array}{l}p 1-2=0,005 \\
p 1-3=0,021\end{array}$ & 0,0121 \\
\hline & $0,06 \pm 0,05$ & $0,10 \pm 0,20$ & $0,08 \pm 0,05$ & $\begin{array}{l}p 1-2=0,003 \\
p 1-3=0,012\end{array}$ & 0,0073 \\
\hline
\end{tabular}

Вместе с тем, доля лиц с разным генезом анемии в группах с обострением и ремиссией ВЗК была сопоставима.

В исследуемых группах пациентов с ВЗК и лиц группы сравнения были изучены уровни жирных кислот в сыворотке крови и мембранах эритроцитов (таблица 2) и их соотношения (таблица 3).

Общим трендом при анализе суммарного содержания ЖК разных классов в мембранах эритроцитов и сыворотке крови следует считать увеличение содержания насыщенных ЖК в период обострения заболевания с последующим снижением при наступлении ремиссии. Напротив, суммарное содержание ненасыщенных ЖК, включая моно-и полиненасыщенные, преимущественно за счет оме- га-6, снижались в образцах пациентов с активным заболеванием по сравнению со здоровыми лицами, но в случае неактивного процесса уровень их повышался по сравнению с таковым в стадии обострения $(p<0,05)$. Суммарное содержание омега-3 ПНЖК в мембранах эритроцитов демонстрировало ту же тенденцию, что и другие ПНЖК, однако, в сыворотке крови отмечено увеличение их процентного содержания как в период обострения, так и в стадию ремиссии. Следует заметить, что сумма уровней эйкозапентаеновой и докозагексаеновой ЖК в мембранах эритроцитов и сыворотке крови имела тенденцию к повышению у пациентов с В3К в обе стадии, но достоверно более высокое содержание EPA+DHA установлено только для мембран эритроцитов пациентов в стадии ремиссии в отличии от здоровых лиц $(p=0,033)$. 
В соответствии с обнаруженными закономерностями изменений основных классов ЖК, изменялись индексы, отражающие их соотношения: отмечено увеличение соотношения насыщенные/ненасыщенные, насыщенные/ полиненасыщенные, омега-3/омега-6 ПНЖК в мембранах эритроцитов и сыворотке крови при обострении заболевания со снижением последних при достижении ремиссии $(p=0,0017-0,05)$. Соотношение омега-6/омега-3 показало инверсную динамику - снижение показателя в активной стадии ВЗК по сравнению со здоровыми лицами $(\mathrm{p}=0,022-0,02)$ и увеличение его значения в стадии ремиссии.

На фоне общих закономерностей выявились особенности изменения уровней отдельных жирных кислот, относящихся к разным классам.

Уровни ряда насыщенных ЖК - лауриновой С12:0, миристиновой С14:0, пентадекановой С15:0, маргариновой С17:0 в мембранах эритроцитов и в сыворотке крови оказались ниже у пациентов с В3К (и в обострении, и в ремиссию) по сравнению со здоровыми лицами ( $p=0,0017-0,05)$. Напротив, содержание пальмитиновой С16:0, стеариновой С18:0 и арахиновой С20:0 было выше у пациентов с ВЗК в обеих стадиях, чем в группе сравнения. При этом для пальмитиновой кислоты достоверность различий от здоровых отмечена только для активной стадии $(p=0,0012-0,01)$, для стеариновой и арахиновой - в обе стадии. Следует заметить, что пальмитиновая кислота обнаружила тенденцию к снижению в стадии ремиссии по сравнению с обострением в сыворотке крови $(p=0,083)$, тот же тренд, но в мембранах эритроцитов отмечен для арахиновой ЖК ( $\mathrm{p}=$ 0,073). Поскольку процентное содержание пальмитиновой и стеариновой ЖК существенно превосходило долю остальных насыщенных ЖК, они определили общую тенденцию изменений по данному классу ЖК.

При анализе уровней отдельных жирных кислот, относящихся к мононенасыщенным, установлено, что содержание 7-пальмитоолеиновой С16:1;7, 9-пальми-

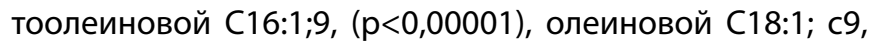
элаидиновой C18:1; t9 оказалось достоверно ниже у пациентов с ВЗК в обе стадии, чем у здоровых лиц. При этом для двух первых кислот достоверное снижение выявлено только в мембранах эритроцитов при той же тенденции в сыворотке. Достоверно сниженные уровни олеиновой ЖК в мембранах эритроцитов отмечены для обеих стадий заболевания ( $p=0,017$ для обострения и $\mathrm{p}<0,05$ для ремиссии), в сыворотке достоверное снижение выявлено лишь в период обострения $(p=0,04)$, в неактивной стадии находясь на уровне тенденции $(\mathrm{p}=$ 0,09). Содержание элаидиновой ЖК оказалось достоверно ниже такового у здоровых только в мембранах эритроцитов пациентов с активными В3К $(p=0,044)$.
Анализ уровней отдельных исследованных омега-3 ПнжК выявил разнонаправленные изменения. Уровень $a$-линоленовой ЖК (C18:3n3) у пациентов с В3К в активной стадии был достоверно ниже такового у здоровых лиц в мембранах эритроцитов $(p=0,023)$ и сыворотке крови ( $p=0,0002)$. В стадию ремиссии отмечено достоверное увеличение процентного содержания этой кислоты в мембранах эритроцитов по сравнению с обострением $(p=0,014)$, в сыворотке при том же тренде уровень достоверности не достигнут, тем не менее эта величина выявила тенденцию к снижению по сравнению со здоровыми ( $p=0,09)$. Уровень эйкозапентаеновой ЖК (C20:5n3) несколько повышался по оси «здоровые-обострение В3К -ремиссия ВЗК» без достоверности различий. Та же тенденция отмечена в отношении уровня докозапентаеновой ЖК (C22:5n3) в мембранах эритроцитов. В сыворотке крови ее содержание в стадии ремиссии было выше, чем у здоровых лиц ( $p=0,017)$ и при обострении В3К $(p<0,05)$. Для докозагексаеновой $(C 22: 6 n 3)$ выявлено достоверно более высокое содержание в мембранах эритроцитов пациентов с неактивными В3К по сравнению со здоровыми ( $p=0,044)$, в сыворотке крови ее уровни были достоверно выше, чем в группе контроля, как в стадию обострения $(p=0,02)$, так и ремиссии $(p=0,03)$.

Анализ содержания отдельных омега-6 ПНЖК позволил выявить также различные тренды.

Уровень гексадекадиеновой ЖК (C16:2n-6) в мембранах эритроцитов оказался достоверно выше у пациентов с ремиссии В3К, чем у здоровых лиц $(p=0,016)$ и при обострении В3К $(p=0,036)$. В сыворотке же наблюдалось достоверное снижение содержания данной ЖК при заболеваниях кишечника в активной стадии по сравнению со здоровыми лицами $(p=0,019)$.

Содержание линолевой ЖК (C18:2n-6) в мембранах эритроцитов и сыворотке крови оказалось ниже у пациентов ВЗК независимо от стадии, чем у здоровых лиц $(p=0,001-0,05)$, при этом в сыворотке крови отмечена тенденция к некоторому нарастанию уровня этой ЖК у пациентов в стадии ремиссии по сравнению с обострением $(p=0,09)$.

Процентное содержание докодиеновой ЖК С20:2n-6 не отличалось в обследуемых группах, следует лишь отметить тенденцию к его увеличению в сыворотке крови пациентов с ВЗК в стадии ремиссии по сравнению с обострением $(p=0,07)$.

Уровни дигомо-ү-линоленовой С20:3n-6 в изучаемых группах оказались сопоставимы между собой.

Интересным оказалось изменение уровней арахидоновой ЖК (C20:4n-6) — некоторое снижение ее содержа- 
Таблица 4. Корреляции уровней жирных кислот мембран эритроцитов и сыворотки крови с маркерами воспаления у пациентов с ВЗК

\begin{tabular}{|c|c|c|c|c|c|c|c|}
\hline 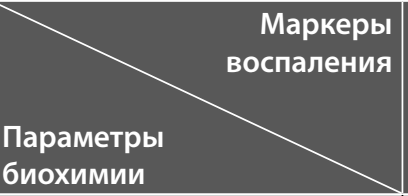 & $\begin{array}{l}\text { Коли- } \\
\text { чество } \\
\text { эритро- } \\
\text { цитов, } \\
\text { х1012/л }\end{array}$ & $\begin{array}{l}\text { Уровень } \\
\text { гемоглоби- } \\
\text { на, г/л }\end{array}$ & СОЭ, мм/ч & $\begin{array}{l}\text { Количество } \\
\text { лейкоцитов, } \\
\text { х109/л }\end{array}$ & $\begin{array}{l}\text { C-реактив- } \\
\text { ный белок, } \\
\text { мг/л }\end{array}$ & $\begin{array}{l}\text { Фибриноген, } \\
\text { г/л }\end{array}$ & $\begin{array}{l}\text { Фекальный } \\
\text { кальпротек- } \\
\text { тин, мкг/г }\end{array}$ \\
\hline $\begin{array}{l}\text { C12:0 Додекановая } \\
\text { (Лауриновая) }\end{array}$ & \begin{tabular}{|l|}
0,187 \\
$(0,009)$ \\
0,173 \\
$(0,017)$
\end{tabular} & \begin{tabular}{|l}
0,326 \\
$(0,0001)$ \\
0,274 \\
$(0,0001)$
\end{tabular} & \begin{tabular}{|l}
$-0,226$ \\
$(0,002)$ \\
$-0,160$ \\
$(0,027)$
\end{tabular} & $H / 3$ & $\begin{array}{l}-0,167 \\
(0,027) \\
H / 3\end{array}$ & $\begin{array}{l}-0,310 \\
(0,0001) \\
-0,230 \\
(0,008)\end{array}$ & $\begin{array}{l}-0,171 \\
(0,071) \\
H / 3\end{array}$ \\
\hline $\begin{array}{l}\text { C14:0 Тетрадекановая } \\
\text { (Миристиновая) }\end{array}$ & $\begin{array}{l}H / 3 \\
0,169 \\
(0,019)\end{array}$ & $\begin{array}{l}0,119 \\
(0,096) \\
0,246 \\
(0,001) \\
\end{array}$ & $\begin{array}{l}H / 3 \\
-0,154 \\
(0,033)\end{array}$ & $H / 3$ & $H / 3$ & $\begin{array}{l}-0,205 \\
(0,019) \\
H / 3\end{array}$ & $H / 3$ \\
\hline C15:0 Пентадекано-вая & $\begin{array}{l}0,162 \\
(0,024) \\
H / 3\end{array}$ & $\begin{array}{l}0,234 \\
(0,001) \\
H / 3\end{array}$ & $\begin{array}{l}-0,147 \\
(0,042) \\
H / 3\end{array}$ & $\mathrm{H} / 3$ & $\begin{array}{l}-0,192 \\
(0,011) \\
H / 3\end{array}$ & $\begin{array}{l}-0,305 \\
(0,001) \\
H / 3\end{array}$ & $H / 3$ \\
\hline $\begin{array}{l}\text { C16:0 Гексадекановая } \\
\text { (Пальмитиновая) }\end{array}$ & $\begin{array}{l}-0,223 \\
(0,002) \\
-0,184 \\
(0,011)\end{array}$ & $\begin{array}{l}H / 3 \\
-0,233 \\
(0,001)\end{array}$ & \begin{tabular}{|l}
0,257 \\
$(0,0001)$ \\
0,339 \\
$(0,0001)$
\end{tabular} & \begin{tabular}{|l}
$H / 3$ \\
0,165 \\
$(0,021)$
\end{tabular} & $\begin{array}{l}H / 3 \\
0,265 \\
(0,0001)\end{array}$ & \begin{tabular}{|l}
$H / 3$ \\
0,281 \\
$(0,001)$
\end{tabular} & $\begin{array}{l}H / 3 \\
0,255 \\
(0,007)\end{array}$ \\
\hline $\begin{array}{l}\text { C16:1;7 Цис-7-гексадекановая } \\
\text { (7-Пальмитоолеиновая) }\end{array}$ & $\begin{array}{l}0,211 \\
(0,003) \\
0,171 \\
(0,018)\end{array}$ & $\begin{array}{l}0,296 \\
(0,0001) \\
0,142 \\
(0,049)\end{array}$ & $\begin{array}{l}-0,213 \\
(0,003) \\
H / 3\end{array}$ & $H / 3$ & $\begin{array}{l}-0,205 \\
(0,007) \\
H / 3\end{array}$ & $\begin{array}{l}-0,239 \\
(0,006) \\
H / 3\end{array}$ & $\begin{array}{l}-0,158 \\
(0,096) \\
H / 3\end{array}$ \\
\hline $\begin{array}{l}\text { C16:1;9 Цис-9-гексадекановая } \\
\text { (Пальмитоолеиновая) }\end{array}$ & $\begin{array}{l}0,236 \\
(0,001) \\
0,138 \\
(0,057)\end{array}$ & \begin{tabular}{|l}
0,372 \\
$(0,0001)$ \\
0,212 \\
$(0,003)$
\end{tabular} & $\begin{array}{l}-0,229 \\
(0,001) \\
H / 3\end{array}$ & $H / 3$ & $\begin{array}{l}-0,154 \\
(0,043) \\
H / 3\end{array}$ & $\begin{array}{l}-0,34 \\
(0,0001) \\
H / 3\end{array}$ & $H / 3$ \\
\hline $\begin{array}{l}\text { C17:0 Гептадекановая } \\
\text { (Маргариновая) }\end{array}$ & $\begin{array}{l}0,174 \\
(0,016) \\
H / 3\end{array}$ & $\begin{array}{l}0,217 \\
(0,002) \\
H / 3\end{array}$ & $\begin{array}{l}-0,195 \\
(0,007) \\
H / 3\end{array}$ & $H / 3$ & $\begin{array}{l}-0,179 \\
(0,018) \\
H / 3\end{array}$ & $\begin{array}{l}-0,223 \\
(0,010) \\
H / 3\end{array}$ & $\mathrm{H} / 3$ \\
\hline $\begin{array}{l}\text { C16:2;9,12 (n-6) } \\
\text { Гексадекадиеновая }\end{array}$ & $\begin{array}{l}H / 3 \\
0,151 \\
(0,037)\end{array}$ & $\begin{array}{l}H / 3 \\
0,218 \\
(0,002)\end{array}$ & $\begin{array}{l}H / 3 \\
-0,137 \\
(0,058)\end{array}$ & $\mathrm{H} / 3$ & $H / 3$ & $H / 3$ & $\begin{array}{l}0,207 \\
(0,028) \\
H / 3\end{array}$ \\
\hline $\begin{array}{l}\text { C18:0 Октадекановая } \\
\text { (Стеариновая) }\end{array}$ & $\begin{array}{l}-0,214 \\
(0,003) \\
-0,269 \\
(0,0001)\end{array}$ & $\begin{array}{l}-0,226 \\
(0,001) \\
-0,3 \\
(0,0001)\end{array}$ & $\begin{array}{l}0,18 \\
(0,012) \\
0,282 \\
(0,0001)\end{array}$ & $H / 3$ & $\begin{array}{l}0,143 \\
(0,06) \\
0,21 \\
(0,006)\end{array}$ & $\begin{array}{l}0,252 \\
(0,004) \\
0,303 \\
(0,0001)\end{array}$ & $H / 3$ \\
\hline $\begin{array}{l}\text { с18:1; с9 Цис-9- } \\
\text { октадекановая } \\
\text { (Олеиновая) }\end{array}$ & $\begin{array}{l}0,192 \\
(0,007) \\
0,213 \\
(0,003)\end{array}$ & $\begin{array}{l}0,218 \\
(0,002) \\
0,252 \\
(0,0001)\end{array}$ & $\begin{array}{l}-0,218 \\
(0,002) \\
-0,15 \\
(0,038)\end{array}$ & $\mathrm{H} / 3$ & $\begin{array}{l}H / 3 \\
-0,141 \\
(0,065)\end{array}$ & $\begin{array}{l}-0,219 \\
(0,012) \\
-0,277 \\
(0,001)\end{array}$ & $\mathrm{H} / 3$ \\
\hline $\begin{array}{l}\text { C18:1; t9 Транс-9- } \\
\text { октадекановая } \\
\text { (Элаидиновая) }\end{array}$ & $\mathrm{H} / 3$ & $\begin{array}{l}H / 3 \\
0,121 \\
(0,093)\end{array}$ & $\mathrm{H} / 3$ & $\mathrm{H} / 3$ & $H / 3$ & $\mathrm{H} / 3$ & $\begin{array}{l}0,159 \\
(0,095) \\
H / 3\end{array}$ \\
\hline $\begin{array}{l}\text { C18:2;9,12 (n-6) } \\
\text { Октадекадиеновая } \\
\text { (Линолевая) }\end{array}$ & $\begin{array}{l}0,221 \\
(0,002) \\
0,182 \\
(0,012)\end{array}$ & $\begin{array}{l}0,186 \\
(0,009) \\
0,212 \\
(0,003)\end{array}$ & $\begin{array}{l}-0,288 \\
(0,0001) \\
-0,348 \\
(0,0001)\end{array}$ & $\begin{array}{l}H / 3 \\
-0,143 \\
(0,047)\end{array}$ & $\begin{array}{l}-0,228 \\
(0,002) \\
-0,301 \\
(0,0001)\end{array}$ & $\begin{array}{l}-0,245 \\
(0,005) \\
-0,303 \\
(0,0001)\end{array}$ & $\begin{array}{l}-0,164 \\
(0,084) \\
-0,228 \\
(0,016)\end{array}$ \\
\hline \multicolumn{8}{|c|}{$\begin{array}{l}\text { Примечания. В круглых скобках указан показатель достоверности данного коэффициента корреляции, н/3 — корреляция } \\
\text { статистически незначима. }\end{array}$} \\
\hline
\end{tabular}


Таблица 4 (продолжение).

Корреляции уровней жирных кислот мембран эритроцитов и сыворотки крови с маркерами воспаления у пациентов с В3К

\begin{tabular}{|c|c|c|c|c|c|c|c|}
\hline Параметры & $\begin{array}{l}\text { Коли- } \\
\text { чество } \\
\text { эритро- } \\
\text { цитов, } \\
\text { х1012/л }\end{array}$ & $\begin{array}{l}\text { Уровень } \\
\text { гемоглоби- } \\
\text { на, г/л }\end{array}$ & $\operatorname{coЭ}$, мм/ч & $\begin{array}{l}\text { Количество } \\
\text { лейкоцитов, } \\
\text { х109/л }\end{array}$ & $\begin{array}{l}\text { С-реактив- } \\
\text { ный белок, } \\
\text { мг/л }\end{array}$ & $\begin{array}{l}\text { Фибриноген, } \\
\text { г/л }\end{array}$ & $\begin{array}{l}\text { Фекальный } \\
\text { кальпротек- } \\
\text { тин, мкг/г }\end{array}$ \\
\hline $\begin{array}{l}\text { С20:0 (Эйкозановая, } \\
\text { Арахиновая) }\end{array}$ & \begin{tabular}{|l|}
$-0,215$ \\
$(0,003)$ \\
$-0,183$ \\
$(0,011)$
\end{tabular} & $\begin{array}{l}-0,316 \\
(0,0001) \\
-0,223 \\
(0,002)\end{array}$ & \begin{tabular}{|l|}
0,187 \\
$(0,009)$ \\
0,212 \\
$(0,003)$
\end{tabular} & $H / 3$ & $H / 3$ & $\begin{array}{l}0,259 \\
(0,003) \\
0,189 \\
(0,031)\end{array}$ & $H / 3$ \\
\hline $\begin{array}{l}\text { C18:3;6,9,12 (n-3) } \\
\text { Октадекатриеновая } \\
\text { (а-Линоленовая) }\end{array}$ & $\begin{array}{l}0,18 \\
(0,012) \\
0,279 \\
(0,0001) \\
\end{array}$ & $\begin{array}{l}0,235 \\
(0,001) \\
0,407 \\
(0,0001) \\
\end{array}$ & $\begin{array}{l}-0,211 \\
(0,003) \\
-0,279 \\
(0,0001) \\
\end{array}$ & $H / 3$ & $\begin{array}{l}-0,172 \\
(0,023) \\
-0,208 \\
(0,005) \\
\end{array}$ & \begin{tabular}{|l|}
$-0,2$ \\
$(0,022)$ \\
$-0,324$ \\
$(0,0001)$ \\
\end{tabular} & $\begin{array}{l}-0,191 \\
(0,044) \\
-0,246 \\
(0,009)\end{array}$ \\
\hline $\begin{array}{l}\text { C20:2;11,14 (n-6) } \\
\text { (Докодиеновая) }\end{array}$ & $\mathrm{H} / 3$ & $\mathrm{H} / 3$ & $\begin{array}{l}/ 3 \\
-0,139 \\
(0,056)\end{array}$ & $\mathrm{H} / 3$ & $H / 3$ & $\mathrm{H} / 3$ & $H / 3$ \\
\hline 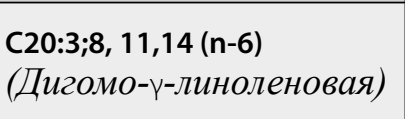 & $\begin{array}{l}H / 3 \\
0,129 \\
(0,075)\end{array}$ & $\mathrm{H} / 3$ & $\mathrm{H} / 3$ & $H / 3$ & $H / 3$ & $H / 3$ & $H / 3$ \\
\hline 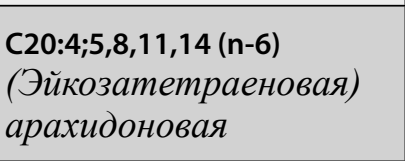 & $\begin{array}{l}0,126 \\
(0,081) \\
0,145 \\
(0,045)\end{array}$ & $\mathrm{H} / 3$ & \begin{tabular}{|l|}
$-0,144$ \\
$(0,046)$ \\
$-0,12$ \\
$(0,098)$
\end{tabular} & $H / 3$ & $H / 3$ & $H / 3$ & $\begin{array}{l}H / 3 \\
-0,159 \\
(0,096)\end{array}$ \\
\hline 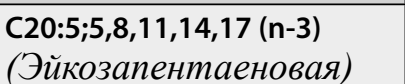 & $\mathrm{H} / 3$ & $\mathrm{H} / 3$ & $\mathrm{H} / 3$ & $\mathrm{H} / 3$ & $\mathrm{H} / 3$ & $\mathrm{H} / 3$ & $\mathrm{H} / 3$ \\
\hline $\begin{array}{l}\mathrm{C} 22: 4 ; 7,10,13,16 \text { (n-6) } \\
\text { (Докозатетраеновая) }\end{array}$ & \begin{tabular}{|l|}
0,13 \\
$(0,071)$ \\
0,172 \\
$(0,017)$ \\
\end{tabular} & $\mathrm{H} / 3$ & $\mathrm{H} / 3$ & $\mathrm{H} / 3$ & $H / 3$ & $H / 3$ & $H / 3$ \\
\hline $\begin{array}{l}\text { С22:5;7,10,13,16,19 (n-3) } \\
\text { (Докозапентаеновая) }\end{array}$ & $\mathrm{H} / 3$ & $\mathrm{H} / 3$ & $\mathrm{H} / 3$ & $\mathrm{H} / 3$ & $\mathrm{H} / 3$ & $\begin{array}{l}0,147 \\
(0,095) \\
H / 3\end{array}$ & $\mathrm{H} / 3$ \\
\hline 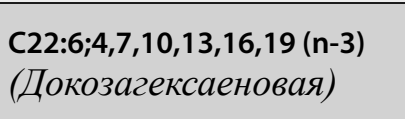 & $H / 3$ & $\begin{array}{l}/ 3 \\
-0,144 \\
(0,045)\end{array}$ & $\begin{array}{l}H / 3 \\
0,173 \\
(0,017)\end{array}$ & $\mathrm{H} / 3$ & $\begin{array}{l}/ 3 \\
0,145 \\
(0,057)\end{array}$ & \begin{tabular}{|l}
$H / 3$ \\
0,222 \\
$(0,011)$
\end{tabular} & $H / 3$ \\
\hline насыщенные & $\begin{array}{l}-0,228 \\
(0,001) \\
-0,226 \\
(0,002) \\
\end{array}$ & $\begin{array}{l}-0,179 \\
(0,012) \\
-0,272 \\
(0,0001) \\
\end{array}$ & \begin{tabular}{|l|}
0,247 \\
$(0,001)$ \\
0,315 \\
$(0,0001)$ \\
\end{tabular} & $\begin{array}{l}H / 3 \\
0,121 \\
(0,093)\end{array}$ & \begin{tabular}{|l|}
0,137 \\
$(0,072)$ \\
0,251 \\
$(0,001)$ \\
\end{tabular} & \begin{tabular}{|l|}
0,191 \\
$(0,029)$ \\
0,292 \\
$(0,001)$ \\
\end{tabular} & $\begin{array}{l}H / 3 \\
0,19 \\
(0,045)\end{array}$ \\
\hline ненасыщенные & $\begin{array}{l}0,226 \\
(0,002) \\
0,225 \\
(0,002) \\
\end{array}$ & \begin{tabular}{|l|}
0,177 \\
$(0,013)$ \\
0,272 \\
$(0,0001)$ \\
\end{tabular} & \begin{tabular}{|l|}
$-0,248$ \\
$(0,0001)$ \\
$-0,316$ \\
$(0,0001)$ \\
\end{tabular} & $\begin{array}{l}H / 3 \\
-0,122 \\
(0,091)\end{array}$ & $\begin{array}{l}-0,135 \\
(0,076) \\
-0,252 \\
(0,001) \\
\end{array}$ & $\begin{array}{l}-0,19 \\
(0,03) \\
-0,292 \\
(0,001) \\
\end{array}$ & $\begin{array}{l}H / 3 \\
-0,191 \\
(0,044)\end{array}$ \\
\hline мононенасыщенные & \begin{tabular}{|l|}
0,225 \\
$(0,002)$ \\
0,232 \\
$(0,001)$ \\
\end{tabular} & \begin{tabular}{|l|}
0,226 \\
$(0,0001)$ \\
0,266 \\
$(0,0001)$ \\
\end{tabular} & $\begin{array}{l}0,232 \\
(0,001) \\
-0,13 \\
(0,073) \\
\end{array}$ & $\mathrm{H} / 3$ & $\begin{array}{l}-0,148 \\
(0,051) \\
H / 3\end{array}$ & $\begin{array}{l}-0,246 \\
(0,005) \\
-0,247 \\
(0,005) \\
\end{array}$ & $\mathrm{H} / 3$ \\
\hline полиненасыщенные & $\begin{array}{l}0,194 \\
(0,007) \\
0,186 \\
(0,01)\end{array}$ & $\begin{array}{l}H / 3 \\
0,211 \\
(0,003)\end{array}$ & $\begin{array}{l}-0,182 \\
(0,011) \\
-0,336 \\
(0,0001)\end{array}$ & $\begin{array}{l}H / 3 \\
-0,144 \\
(0,046)\end{array}$ & $\begin{array}{l}H / 3 \\
-0,274 \\
(0,0001)\end{array}$ & $\begin{array}{l}H / 3 \\
-0,232 \\
(0,008)\end{array}$ & $\begin{array}{l}H / 3 \\
-0,201 \\
(0,035)\end{array}$ \\
\hline \multicolumn{8}{|c|}{$\begin{array}{l}\text { Примечания. В круглых скобках указан показатель достоверности данного коэффициента корреляции, н/3 - корреляция } \\
\text { статистически незначима. }\end{array}$} \\
\hline
\end{tabular}


Таблица 4 (продолжение).

Корреляции уровней жирных кислот мембран эритроцитов и сыворотки крови с маркерами воспаления у пациентов с ВЗК

\begin{tabular}{|c|c|c|c|c|c|c|c|}
\hline $\begin{array}{l}\text { Маркеры } \\
\text { Парампетрыления } \\
\text { биохимии }\end{array}$ & $\begin{array}{l}\text { Коли- } \\
\text { чество } \\
\text { эритро- } \\
\text { цитов, } \\
\text { х1012/л }\end{array}$ & $\begin{array}{l}\text { Уровень } \\
\text { гемоглоби- } \\
\text { на, г/л }\end{array}$ & СОЭ, мм/ч & $\begin{array}{l}\text { Количество } \\
\text { лейкоцитов, } \\
\text { х109/л }\end{array}$ & $\begin{array}{l}\text { С-реактив- } \\
\text { ный белок, } \\
\text { мг/л }\end{array}$ & $\begin{array}{l}\text { Фибриноген, } \\
\text { г/л }\end{array}$ & $\begin{array}{l}\text { Фекальный } \\
\text { кальпротек- } \\
\text { тин, мкг/г }\end{array}$ \\
\hline омега-3 & $H / 3$ & $\mathrm{H} / 3$ & $H / 3$ & $H / 3$ & $H / 3$ & \begin{tabular}{|l|}
$/ 3$ \\
0,153 \\
$(0,082)$ \\
\end{tabular} & $H / 3$ \\
\hline омега-6 & \begin{tabular}{|l|}
0,203 \\
$(0,005)$ \\
0,196 \\
$(0,007)$ \\
\end{tabular} & \begin{tabular}{|l}
$H / 3$ \\
0,212 \\
$(0,003)$
\end{tabular} & \begin{tabular}{|l|}
$-0,221$ \\
$(0,002)$ \\
$-0,341$ \\
$(0,0001)$ \\
\end{tabular} & $\begin{array}{l}H / 3 \\
-0,141 \\
(0,05)\end{array}$ & $\begin{array}{l}-0,126 \\
(0,097) \\
-0,294 \\
(0,001) \\
\end{array}$ & $\begin{array}{l}-0,16 \\
(0,068) \\
-0,262 \\
(0,003) \\
\end{array}$ & $\begin{array}{l}H / 3 \\
-0,216 \\
(0,023)\end{array}$ \\
\hline омега-3(EPA+DHA) & $H / 3$ & $\mathrm{H} / 3$ & $\mathrm{H} / 3$ & $H / 3$ & $H / 3$ & $\begin{array}{l}H / 3 \\
0,211 \\
(0,016) \\
\end{array}$ & $H / 3$ \\
\hline омега-6/омега-3 & \begin{tabular}{|l}
$H / 3$ \\
0,146 \\
$(0,044)$
\end{tabular} & $H / 3$ & $\begin{array}{l}-0,222 \\
(0,002) \\
-0,187 \\
(0,01) \\
\end{array}$ & $H / 3$ & $\begin{array}{l}-0,217 \\
(0,004) \\
-0,217 \\
(0,004) \\
\end{array}$ & $\begin{array}{l}-0,276 \\
(0,001) \\
-0,262 \\
(0,003) \\
\end{array}$ & $\begin{array}{l}H / 3 \\
-0,189 \\
(0,047)\end{array}$ \\
\hline насыщ./ненасыщ. & $\begin{array}{l}-0,231 \\
(0,001) \\
-0,230 \\
(0,001) \\
\end{array}$ & \begin{tabular}{|l|}
$-0,179$ \\
$(0,012)$ \\
$-0,273$ \\
$(0,0001)$ \\
\end{tabular} & \begin{tabular}{|l|}
0,245 \\
$(0,001)$ \\
0,309 \\
$(0,0001)$ \\
\end{tabular} & $H / 3$ & \begin{tabular}{|l|}
0,135 \\
$(0,076)$ \\
0,243 \\
$(0,001)$ \\
\end{tabular} & \begin{tabular}{|l|}
0,19 \\
$(0,03)$ \\
0,29 \\
$(0,001)$ \\
\end{tabular} & $\begin{array}{l}H / 3 \\
0,192 \\
(0,044)\end{array}$ \\
\hline насыщ./полиненасыщ. & $\begin{array}{l}-0,211 \\
(0,003) \\
-0,213 \\
(0,003) \\
\end{array}$ & \begin{tabular}{|l|}
$-0,133$ \\
$(0,064)$ \\
$-0,251$ \\
$(0,0001)$ \\
\end{tabular} & \begin{tabular}{|l|}
0,208 \\
$(0,004)$ \\
0,34 \\
$(0,0001)$ \\
\end{tabular} & $\begin{array}{l}H / 3 \\
0,139 \\
(0,053)\end{array}$ & $\begin{array}{l}H / 3 \\
0,272 \\
(0,0001)\end{array}$ & $\begin{array}{l}H / 3 \\
0,274 \\
(0,002)\end{array}$ & $\begin{array}{l}H / 3 \\
0,213 \\
(0,025)\end{array}$ \\
\hline омега-3/омега-6 & $\begin{array}{l}H / 3 \\
-0,171 \\
(0,022)\end{array}$ & $\begin{array}{l}H / 3 \\
-0,133 \\
(0,073)\end{array}$ & $\begin{array}{l}0,227 \\
(0,002) \\
0,191 \\
(0,01)\end{array}$ & $H / 3$ & $\begin{array}{l}0,207 \\
(0,007) \\
0,207 \\
(0,007)\end{array}$ & $\begin{array}{l}0,25 \\
(0,005) \\
0,257 \\
(0,003)\end{array}$ & $\begin{array}{l}H / 3 \\
0,18 \\
(0,058)\end{array}$ \\
\hline \multicolumn{8}{|c|}{$\begin{array}{l}\text { Примечания. В круглых скобках указан показатель достоверности данного коэффициента корреляции, н/3 - корреляция } \\
\text { статистически незначима. }\end{array}$} \\
\hline
\end{tabular}

ния в мембранах эритроцитов у пациентов с активными ВЗК по сравнению со здоровыми лицами сменилось нарастанием ее значений в стадии ремиссии с достоверным отличием от стадии обострения $(p=0,04)$. В сыворотке крови выявлен достоверно более высокий уровень C20:4n-6 у лиц с В3К в стадии ремиссии, чем в группе контроля $(p=0,04)$ и в стадии обострения $(p=0,04)$.

Такая же тенденция установлена в отношении эритроцитарного содержания докозатетраеновой ЖК (С22:4 n-6) при патологии кишечника в неактивной стадии ее уровень был достоверно выше, чем у здоровых лиц $(p=0,048)$ и при активном В3К $(p=0,022)$. В сыворотке крови уровни C22:4 n-6 в группах не различались.

Исследованы корреляции уровней жирных кислот в мембранах эритроцитов и сыворотке крови с некото- рыми показателями красной крови и маркерами воспаления (таблица 4). Суммарное содержание насыщенных ЖК обратно коррелировало с количеством эритроцитов, уровнем гемоглобина $(r=-0,226, p=0,002$ и $r=-0,272$, $\mathrm{p}<0,0001$, соответственно, для ЖК сыворотки крови). Ассоциации же с маркерами воспаления (СОЭ, СРБ, фибриноген) оказались прямыми, как для мембран эритроцитов, так и сыворотки крови (в сыворотке крови корреляции с СОЭ r=0,315, p<0,0001; с СРБ r=0,251, p<0,001; с уровнем фибриногена $r=0,292, p<0,001$; с уровнем фекального кальпротектина $r=0,190, p=0,045)$. Для пальмитиновой, стеариновой, арахиновой ЖК прослеживался тот же характер связей. При этом, кроме вышеописанных маркеров воспаления, уровень пальмитиновой кислоты коррелировал с количеством лейкоцитов $\mathrm{r}=0,165, \mathrm{p}=0,021$ и кальпротектином - $\mathrm{r}=0,255, \mathrm{p}=0,007$. Сывороточный уровень стеариновой ЖК демонстриро- 
Таблица 5. Характеристики полученных диагностических моделей

\begin{tabular}{|c|c|c|c|}
\hline \multirow{2}{*}{ Параметры моделей } & \multicolumn{3}{|c|}{ Диагностические модели } \\
\hline & M1 & M2 & M3 \\
\hline Группа «negative» & Обострение & Ремиссия & Обострение \\
\hline Группа «positive» & Ремиссия & Контроль & Контроль \\
\hline Диагностическая точность & 0,9626 & 0,9610 & 0,9191 \\
\hline Специфичность & 1,0 & 0,9629 & 0,8889 \\
\hline Чувствительность & 0,9540 & 0,9565 & 0,9390 \\
\hline AUC & 0,9488 & 0,9796 & 0,9627 \\
\hline \multicolumn{4}{|c|}{$\begin{array}{l}\text { Примечание: } \\
\text { М1 - Модель для различения пациентов с В3К в стадии ремиссии от пациентов с ВЗК в стадии обострения } \\
\text { М2 - Модель для различения пациентов с В3К в стадии ремиссии от здоровых лиц } \\
\text { МЗ - Модель для различения пациентов с В3К в стадии обострения от здоровых лиц }\end{array}$} \\
\hline
\end{tabular}

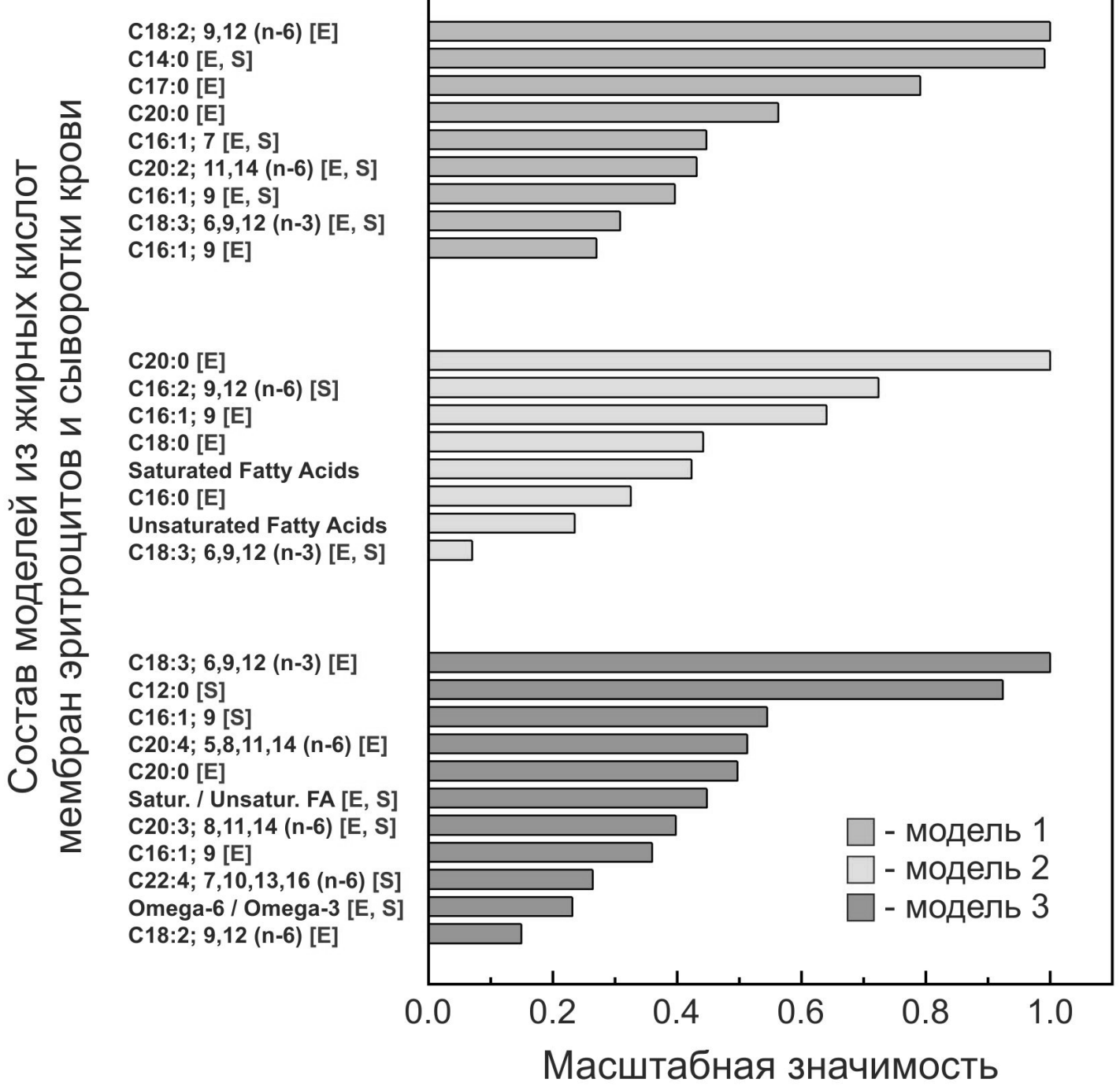

Рис. 1. Диаграммы значимости входных признаков для жирных кислот, включая мембраны эритроцитов (Е) и сыворотки крови (S) для различения пациентов с ВЗК в стадии обострения и ремиссии от здоровых лиц. 


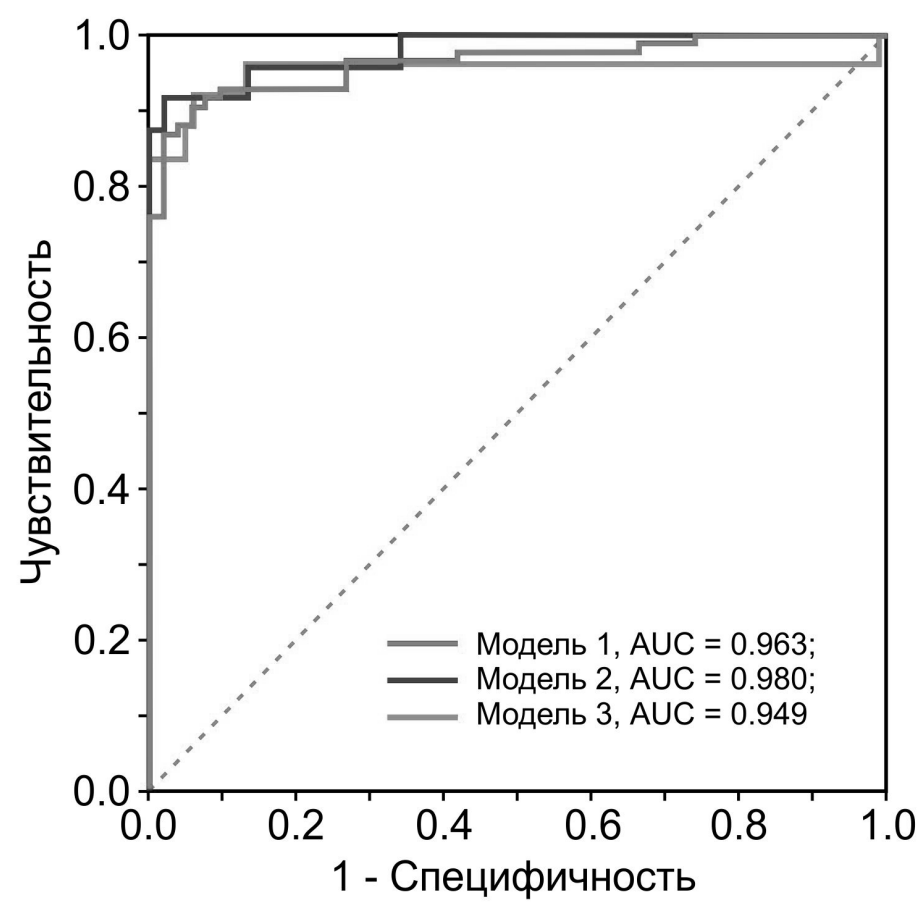

Рис. 2. ROC-кривые для моделей, состоящих из жирных кислот, для различения пациентов с B3K в стадии обострения и ремиссии между собой (Модель 1) и от группы сравнения (Модели 2 и 3 ).

вал высокодостоверные связи с СОЭ $(r=0,282, p<0,0001)$, уровнем СРБ $(r=0,210, p=0,006)$, фибриногена $(r=0,315$, $\mathrm{p}<0,0001)$. Для остальных исследованных ЖК - лауриновой, миристиновой, пентадекановой, маргариновой выявлены прямые корреляции с уровнем гемоглобина и количеством эритроцитов (особенно тесные для эритроцитарных и сывороточных уровней С12:0 и количества эритроцитов - $\mathrm{r}=0,326, \mathrm{p}<0,0001$ и $\mathrm{r}=0,274$, $\mathrm{p}<0,0001)$. Следует заметить, что только эритроцитарные уровни С15:0 и С 17:0 обнаружили корреляции с показателями красной крови и маркерами воспаления. Связь с последними для С12:0, С14:0, С15:0 и С17:0 оказалась обратной.

Суммарное содержание ненасыщенных ЖК (как в целом, так и отдельных классов - моно-, полиненасыщенных) прямо коррелировало с количеством эритроцитов, уровнем гемоглобина и обратно - с маркерами воспаления. Суммарное содержание ПНЖК в сыворотке обнаружило обратные связи с количеством лейкоцитов ( $r=$ $-0,144, p<0,046)$, СОЭ $(r=-0,336, p<0,0001)$, СРБ $(r=-0,274$, $\mathrm{p}<0,0001)$, уровнем фибриногена $(r=-0,232, p<0,008)$, фекального кальпротектина $(r=-0,201, p<0,035)$. Интересно заметить, что суммарное содержание омега-3 ПНЖК проявило ассоциации с маркерами воспаления только в виде тенденций, а сумма сывороточных уровней C20:5n3 и С22:6n3 оказалась прямо связанной с уровнем фибриногена ( $r=0,211, p=0,016)$. Определяющей для ac- социаций ПНЖК оказалась роль суммарного содержания омега-6 ЖК - прямые корреляции с количеством эритроцитов $(r=0,21, p=0,003)$ и содержанием гемоглобина $(r=0,196, p=0,007)$ и обратные - с маркерами воспаления (количества лейкоцитов - $r=-0,141, p<0,05$; СОЭ - r= -0,341, p<0,0001; СРБ - $r=-0,294, p<0,0001$; фибриногена $-r=-0,262, p=0,003$; фекального кальпротектина $-r=-0,216, p=0,023)$.

Следует отметить наличие прямых корреляций между уровнями отдельных мононенасыщенных ЖК - пальмитолеиновой (C16:1;7, С16:1;9), олеиновой (C18:1; с9), полиненасыщенных ЖК - линолевой С18:2n-6, а-линоленовой C18:3n-3, арахидоновой C20:4 n-6 с показателями красной крови и обратных - с маркерами воспаления. Напротив, уровень докозагексаеновой ЖК в сыворотке оказался обратно связанным с уровнем гемоглобина $(r=-0,144, p=0,045)$ и прямо с СОЭ $(r=0,173, p=0,017)$, СРБ $(r=0,145, p=0,057)$, фибриногеном $(r=0,222, p=0,011)$.

Соотношения ЖК - насыщенные/ненасыщенные, насыщенные/полиненасыщенные, омега3/омега6 оказались прямо ассоциированными с уровнями маркеров воспаления.

Проведенный анализ показал, что уровни ряда жирных кислот сыворотки и мембран эритроцитов являются значимыми для различения пациентов с ВЗК от здоро- 
Таблица 6. Состав диагностических моделей и значимость входных значений для жирных кислот, включая мембраны эритроцитов (Е) и сыворотки крови (S) для различения пациентов с ВЗК в стадии обострения и ремиссии от здоровых лиц

\begin{tabular}{|c|c|c|c|c|}
\hline \multirow[t]{2}{*}{ № } & \multirow[t]{2}{*}{ Названия жирных кислот } & \multicolumn{3}{|c|}{$\begin{array}{l}\text { Значимость входных значений для жирных кислот, входящих } \\
\text { в состав моделей }\end{array}$} \\
\hline & & M1 & M2 & M3 \\
\hline 1 & Е С20:0 (Эйкозановая, Арахиновая) & & 0,33 & \\
\hline 2 & $\begin{array}{l}\text { Е С16:1;9 Цис-9-гек-садекановая } \\
\text { (Паль-митоолеиновая) }\end{array}$ & 0,36 & 0,64 & 0,27 \\
\hline 3 & Е С17:0 Гептадекановая (Маргариновая) & & & 0,79 \\
\hline 4 & Е С18:0 Октадекановая (Стеариновая) & & 0,44 & \\
\hline 5 & E C18:2;9,12 (n-6) Октадекадиеновая (Линолевая) & & & 1,00 \\
\hline 6 & Е С20:0 (Эйкозановая, Арахиновая) & 0,50 & 1,00 & 0,56 \\
\hline 7 & $\begin{array}{l}\text { Е С18:3;6,9,12 (n-3) Октадекатриеновая } \\
\text { (а-Линоленовая) }\end{array}$ & 1,00 & & \\
\hline 8 & $\begin{array}{l}\text { Е С20:4;5,8,11,14 (n-6) (Эйкозатетраеновая) } \\
\text { арахидоновая }\end{array}$ & 0,51 & & \\
\hline 9 & Е Суммарное содержание насыщенных ЖК & & 0,42 & \\
\hline 10 & S C12:0 Додекановая (Лауриновая) & 0,92 & & \\
\hline 11 & $\begin{array}{l}\text { S C16:1;9 Цис-9-гек-садекановая (Паль- } \\
\text { митоолеиновая) }\end{array}$ & 0,54 & & \\
\hline 12 & S C16:2;9,12 (n-6) Гексадекадиеновая & & 0,72 & \\
\hline 13 & S C22:4;7,10,13,16 (n-6) (Докозатетраеновая) & 0,26 & & \\
\hline 14 & S Суммарное содержание ненасыщенных ЖK & & 0,24 & \\
\hline 15 & E-S C12:0 Додекановая (Лауриновая) & & & 0,99 \\
\hline 16 & $\begin{array}{l}\text { E-S C16:1;7 Цис-7-гексадекановая } \\
\text { (7-Пальмитоолеиновая) }\end{array}$ & & & 0,45 \\
\hline 17 & $\begin{array}{l}\text { E-S C16:1;9 Цис-9-гек-садекановая (Паль- } \\
\text { митоолеиновая) }\end{array}$ & & & 0,40 \\
\hline 18 & $\begin{array}{l}\text { E-S C18:2;9,12 (n-6) Октадекадиеновая } \\
\text { (Линолевая) }\end{array}$ & 0,15 & & \\
\hline 19 & $\begin{array}{l}\text { E-S C18:3;6,9,12 (n-3) Октадекатриеновая } \\
\text { (а-Линоленовая) }\end{array}$ & & 0,07 & 0,31 \\
\hline 20 & E-S C20:2;11,14 (n-6) (Докодиеновая) & & & 0,43 \\
\hline 21 & E-S C20:3;8, 11,14 (n-6) (Дигомо-ү-линоленовая) & 0,40 & & \\
\hline 22 & E-S омега 6/омега 3 & 0,23 & & \\
\hline 23 & E-S насыщ./ненасыщ. & 0,45 & & \\
\hline
\end{tabular}

вых лиц, другие - для дифференцирования пациентов в стадии обострения от ремиссии. Однако традиционные методы статистической обработки не позволили сформировать диагностические модели, интегрирующие все множество выявленных зависимостей. В связи с этим, для создания диагностических панелей были ис- пользованы методы машинного обучения, основанные на деревьях решений. Среди множества методов одним из наиболее результативных оказался градиентный бустинг, применение которого позволило получить набор диагностических моделей высокой диагностической точности (от 0,91 до 0,96) (таблица 5). 
Построение диагностических моделей для различения пациентов с ВЗК (обострение и ремиссия) от здоровых лиц позволило выявить перечень ЖК и их соотношений, значимых для каждой диагностической модели (таблица 6).

Важно заметить, что в разных парах групп («здоровые-обострение ВЗК», «здоровые-ремиссия ВЗК», «обострение- ремиссия ВЗК») в полученных моделях меняется состав и значимость параметров. В различении пациентов в стадии обострения от здоровых лиц на первое место по значимости выходят линолевая ЖК, отдельные насыщенные ЖК, существенно меньший вклад вносят мононенасыщенныеЖКи а-линоленовая кислота (омега 3). В модели, различающей пациентов с ремиссией ВЗК от здоровых максимальна роль насыщенных и мононенасыщенных ЖК (как отдельных, так и суммарного содержания), вклад ненасыщенных незначителен. Наконец, в дифференцировании пациентов в стадии обострения от ремиссии ВЗК велико значение а-линоленовой кислоты (омега3 ПНЖК), насыщенной ЖК - лауриновой, мононенасыщенной пальмитолеиновой и арахидоновой (ПНЖК омега 6).

Первая диагностическая модель M1 позволила дифференцировать пациентов с ВЗК в стадии обострения от больных с ВЗК в стадии ремиссии. В ее состав вошли уровни а-линоленовой кислоты в мембранах эритроцитов, сывороточное содержание лауриновой, пальмитолеиновой ЖК, уровни арахидоновой и арахиновой ЖК в мембранах эритроцитов, отношение эритроцитарных и сывороточных уровней насыщенные/ненасыщенные ЖК, дигомо-г-линоленовой ЖК, эритроцитарный уровень пальмитоолеиновой, содержание докозатетраеновой ЖК в сыворотке крови, отношение эритроцитарных и сывороточных уровней омега 6/омега 3, содержание линолевой ЖК в мембранах эритроцитов (рисунок 1). При проведении ROC-анализа (рисунок 2) с использованием данной модели AUC составила 0,9488, чувствительность 0,9540, специфичность 1, диагностическая точность - 0,9626 (таблица 5).

Вторая диагностическая модель M2 продемонстрировала возможности различения пациентов с ВЗК в стадии ремиссии от здоровых лиц. При этом наиболее значимыми оказались уровни арахиновой кислоты в мембранах эритроцитов, гексадекадиеновой ЖК в сыворотке крови, эритроцитарное содержание стеариновой ЖК, суммарное содержание насыщенных ЖК в мембранах эритроцитов, уровень пальмитиновой ЖК в эритроцитах, суммарное содержание сывороточных ненасыщенных ЖК, отношение эритроцитарных и сывороточных уровней а-линоленовой кислоты. При проведении ROC-анализа с использованием данной модели при дифференцировании пациентов с обострением ВЗК от здоровых лиц AUC составила 0,9796, чувствитель- ность 0,9565, специфичность 0,9629, диагностическая точность - 0,9610 (таблица 5).

В третьей диагностической модели M3, различающей пациентов в стадии обострения ВЗК от здоровых лиц, наиболее значимыми оказались уровни линолевой кислоты в мембранах эритроцитов, отношение эритроцитарных и сывороточных уровней миристиновой кислоты, содержание маргариновой, арахиновой ЖК в эритроцитах, отношения эритроцитарных и сывороточных уровней 7-пальмитоолеиновой, докодиеновой, пальитоолеиновой, а-линоленовой и содержание пальмитоолеиновой ЖК в эритроцитах. При проведении ROC-анализа с использованием данной модели при дифференцировании пациентов с обострением ВЗК от здоровых лиц AUC составила 0,9627, чувствительность 0,9390, специфичность 0,8889, диагностическая точность - 0,9191.

\section{Обсужление}

В настоящем исследовании изучено процентное содержание каждой из жирных кислот по отношении к сумме всех ЖК, поскольку абсолютные уровни ЖК имеют значительный разброс значений.

В данной работе выявлено повышение суммарного содержания насыщенных ЖК как в мембранах эритроцитов, так и в сыворотке крови у пациентов с В3К наиболее выраженное в стадии обострения, но для ряда ЖК сохраняющееся и в стадии ремиссии по сравнению со здоровыми лицами. Наибольший вклад в это суммарное содержание внесли пальмитиновая, стеариновая и арахиновая ЖК, которые прямо коррелировали с уровнем воспалительных маркеров. Эти находки согласуются с результатами Seimon et al. [26], которые сообщили, что насыщенные жирные кислоты могут способствовать макрофагальному воспалению и липотоксичности. Повышенная токсичность насыщенных ЖК может быть в определенной степени обусловлена тем фактом, что они менее эффективно этерифицируются в триглицериды. Хотя механизмы, лежащие в основе липотоксичности, в настоящее время неизвестны, показано, что накопление пальмитиновой кислоты в макрофагах может быть связано с воспалением в стенке кишки [27]. Высокое процентное содержание пальмитиновой ЖК может индуцировать макрофаги к повышенному выделению воспалительных цитокинов в слизистой оболочке кишечника [27].

Данные Wiese DM. и соавт. [28] о прямых корреляциях сывороточных насыщенных ЖК с уровнем тканевых цитокинов косвенно свидетельствуют о провоспалительном потенциале этого класса ЖК.

Одномоментное повышение уровней С16:0, C18:0, С20:0 косвенно свидетельствует о высокой активно- 


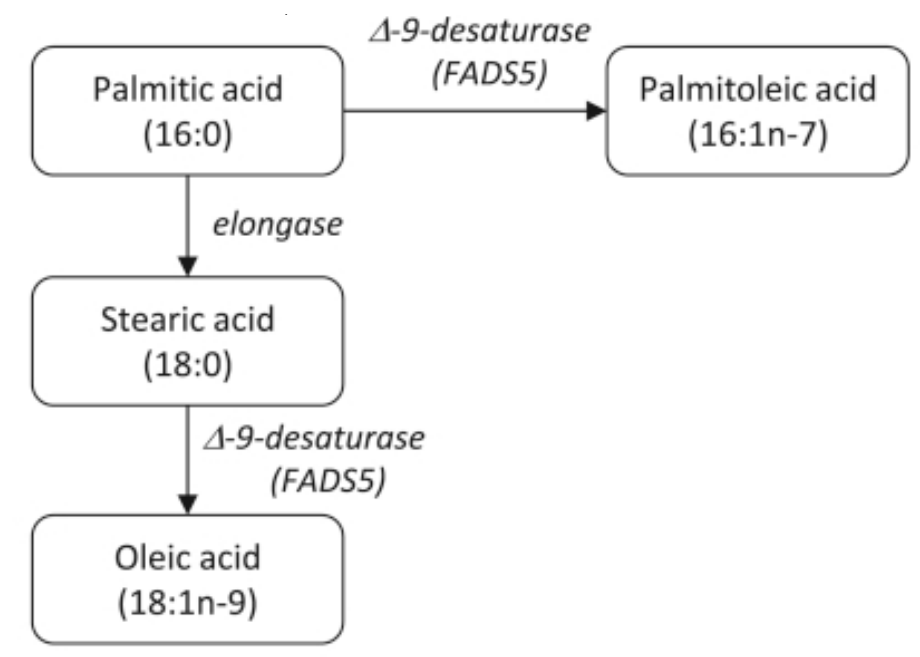

$\omega-6$ PUFA

$\omega-3$ PUFA

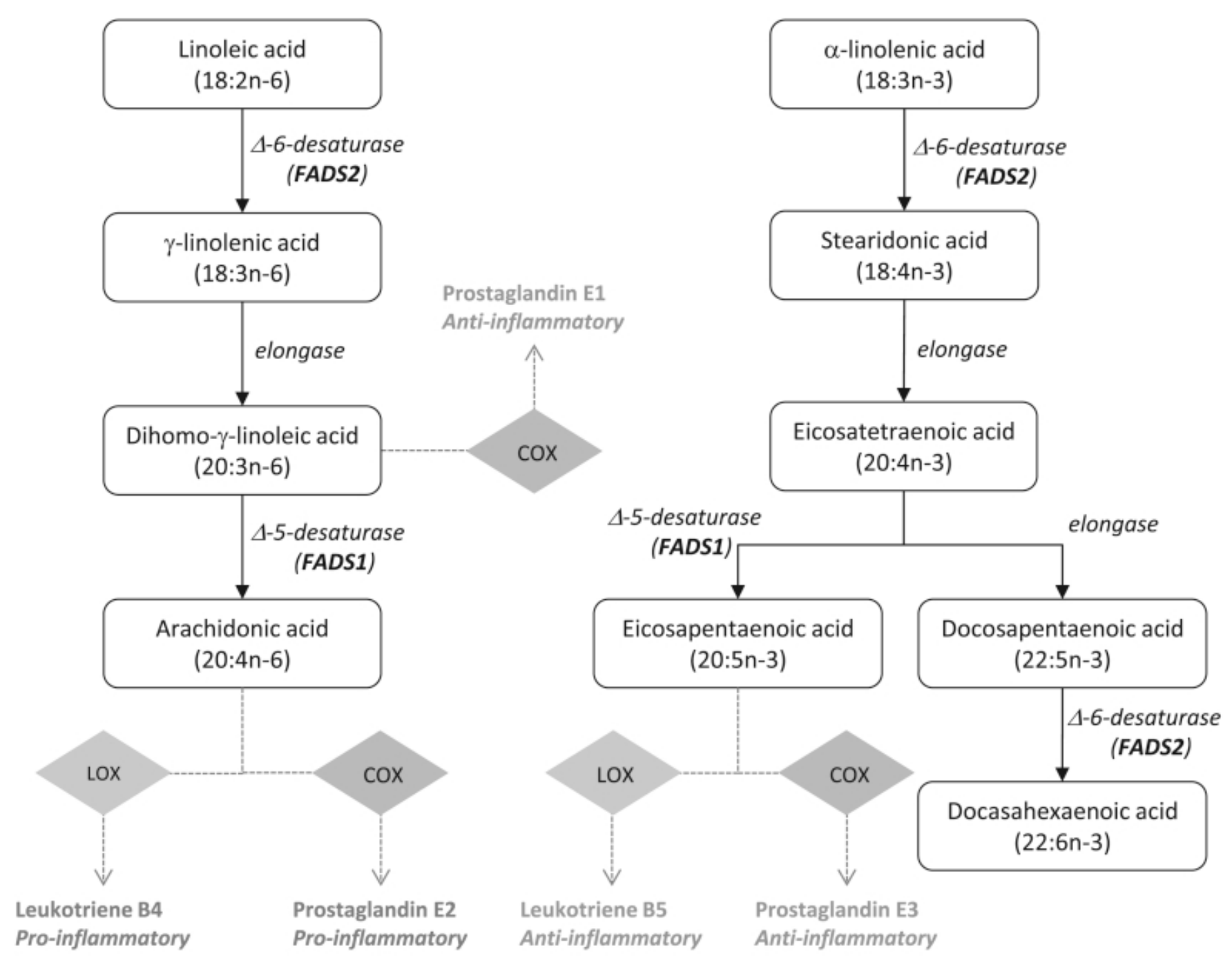

Рис. 3. Схема метаболизма жирных кислот [34] 
сти ферментов элонгаз, удлиняющих углеродную цепь в ходе метаболизма насыщенных ЖК. Вместе с тем, вероятно, активность дельта-9-десатураз (FADSS), метаболизирующих насыщенные ЖК в мононенасыщенные снижена, поскольку уровень последних (олеиновой, пальмитолеиновой, элаидиновой) оказался достоверно ниже при ВЗК, чем у здоровых лиц, особенно в стадии обострения. Показано, что метаболизм насыщенных ЖК с нечетным числом атомов углерода может происходить путем бета-окисления в митохондриях, что обеспечивает быстрое обеспечение энергетических потребностей клетки из-за отсутствия двойных связей [29]. Поэтому одной из возможных причин сниженных уровней С15:0, C17:0 у пациентов с В3К может быть их повышенный расход.

Известно, что мононенасыщенные ЖК могут оказывать эпигенетические воздействия. Так, показано, МНЖК (в том числе, наиболее распространенная олеиновая ЖK - C18:1 n-9), подавляют передачу сигналов PTEN / Akt и регулируют эпителиально-мезенхимальный переход [30].

Сниженные уровни ряда насыщенных ЖК, в частности, миристиновой, у пациентов с ВЗК по сравнению со здоровыми, очевидно, не случайны. Они могут быть связаны с избыточным расходом кислоты в процессе миристоилирования, при котором ЖК ковалентно прикрепляется к N-концевому остатку белка через амидную связь, что, как правило, является необратимой модификацией последнего [31]. N-миристолированные белки обладают множеством важных функций и играют заметную роль в нескольких сигнальных каскадах, включая Src-семейство тирозинкиназ, значимых для прогрессирования ВЗК.

Наиболее интересным оказалось изменение уровней и соотношений ненасыщенных ЖК - обнаружено снижение общего содержания ненасыщенных ЖК преимущественно за счет мононенасыщенных и омега-6, особенно в стадию обострения. Однако, суммарное содержание омега-3 продемонстрировало тенденцию к повышению у пациентов с ВЗК в обе стадии.

Известно, что на состав ПНЖК в плазме или жизненно важных клеточных мембранах может влиять ряд факторов, включая потребление пищи, образ жизни и демографические характеристики [32, 33]. Показано также, что гендерные и присущие поколению различия влияют на предпочтения и привычки в еде [34]. В настоящей работе изучаемые группы были сопоставимы по возрасту и полу для минимизации влияния данных факторов.

Эпидемиологические исследования показали корреляцию распространенности воспалительных за- болеваний кишечника с повышенным потреблением животных жиров и n-6 полиненасыщенных жирных кислот (ПНЖК) [35]. Жирные кислоты, в частности, n-3 и n-6 ПНЖК, опосредуют ряд ключевых биологических процессов, включая эйкозаноидное продуцирование, воспаление, физиологические процессы в клеточной мембране, регуляцию и экспрессию генов [36]. Показано, что длинноцепочечные диетические n-3 ПНЖК ингибируют экспрессию генов, активирующих воспалительные процессы [37]. Механизм, с помощью которого жирные кислоты влияют на течение В3К, до конца не понят, но было высказано предположение, что n-6 ПНЖК способствуют синтезу провоспалительных цитокинов через метаболизм арахидоновой кислоты [38, 39]. Кроме того, n-3 ПНЖК обладают противовоспалительными свойствами: способствуют смещению арахидоновой кислоты из клеточной мембраны с последующим снижением уровня ее производных, влияют на изменчивость клеточной мембраны и способность к связыванию белка, ингибируют NF-к B и снижают активность его ядерных мишеней [40]. В экспериментах in vitro Li Q. и соавт. [41] показали, что n-3 ПНЖК играют важную роль в индуцированных провоспалительными цитокинами дефектах проницаемости и дисфункции эпителиального барьера при болезни Крона, модифицируя липидную среду в мембранных микродоменах плотного соединения.

Недавнее исследование выявило специфические метаболиты арахидоновой кислоты - простагландины E2 и D2, тромбоксан B2 и гидропероксиэкосатетраеновые кислоты (HETE) - повышенными в ткани толстой кишки при язвенном колите и прогнозирующими воспаление толстой кишки [42].

Снижение уровней таких омега-6 ПНЖК, как линолевая, арахидоновая более выраженное в стадию обострения ВЗК по сравнению со здоровыми лицами может быть связано с высокой активностью дельта-6-, дельта-5 десатураз (FADS2, FADS1), элонгаз арахидонового касказа, метаболизирующих линолевую ЖК до арахидоновой. Последняя превращается в провоспалительные лейкотриен B4 $\left(\mathrm{LTB}_{4}\right)$, простагландин $\mathrm{E2}\left(\mathrm{PGE}_{2}\right)$, тромбоксан $\mathrm{A}_{2}\left(\mathrm{TXA}_{2}\right)$ с участием липо- и циклооксигеназ, которые являются общими для омега-6 и омега-3 ПНЖК. «Загруженность» этих ферментных систем метаболизмом омега-6 ПНЖК, вероятно, может объяснить тенденцию к повышению омега-3 ПНЖК у пациентов с В3К как в период обострения, так и в ремиссию. Конкурентное отношение между омега-6 и омега-3 в отношении общих ферментных систем, вероятно, может объяснить недостаточное образование антивоспалительных простагландинов из омега-3 эйкозапентаеновой ЖК (лейкотриена B5 $\left(\mathrm{LTB}_{5}\right)$, простагландина E3 $\left(\mathrm{PGE}_{3}\right)[29,40]$. (рисунок 3) 
Очевидно, что для реализации разных эффектов ПНЖК значимы их уровни. Вероятно, значительное повышение омега-3 ПНЖК при ВЗК как в стадии обострения, так и в ремиссии, не случайно и связано с патогенезом. При высокой концентрации омега-3 ПНЖК могут встраиваться в мембранные фосфолипиды, изменяя их текучесть, в результате чего происходит ингибирование пролиферации Т-клеток. Высокие уровни n-3 PUFA могут подавлять иммунную среду посредством изменений в производстве цитокинов, пролиферации Т-клеток и опосредуемой Т-клеточной цитотоксичности. Кроме того показано, что С22: 6 n-3 также может исключительно подавлять регуляторную функцию Т-лимфоцитов [43].

Другие авторы обнаружили, что чрезмерное воспаление, вызванные диетическим С22: 6 n-3, было связано с измененными популяциями Т-клеток CD8 +, активацией CD69 +, экспрессией FохР3 и активностью клеток FoxP3 + CD25 + CD4 + Treg, экспрессирующих L-селектин. Эти данные свидетельствуют о том, что высокие уровни докозагексаеновой ЖК могут способствовать ослаблению иммунной функции [44].

Результаты настоящей работы согласуются с данными, которые выявили измененные липидные сигнальные каскады у пациентов с В3К [45]. В ряде исследований затрагивался вопрос о том, играет ли докозагексаеновая, длинноцепочечная омега-3 полиненасыщенная жирная кислота, определенную роль в ослаблении воспалительных реакций при В3К $[46,47]$. При использовании нокаут-мышей с интерлейкином (IL)-10 в качестве модели В3К, в недавнем исследовании были отмечены высокие уровни C22:6n3 в плазме и толстой кишке и сделан вывод о том, что липидные медиаторы, такие как C22:6n3 и арахидоновая кислота, могут способствовать развитию В3К [45].

Кроме самих уровней омега-6 и омега-3 ПНЖК, вероятно, велика роль их соотношения в патогенезе ВЗК, что подтверждено в ряде исследований Okuyama Н. И и соавт. [48], Asciutti-Moura L. S и соавт. [49]. Обнаруженные в настоящем исследовании прямые ассоциации индекса омега3/омега 6 с маркерами воспаления косвенно свидетельствуют о значимости этого отношения для развития ВЗК

В ряде работ показано значительное снижение ряда ЖК - пеларгоновой, линолевой, арахидоновой, докозагексаеновой на фоне повышенного уровня ацилкарнитинов в сыворотке крови пациентов с активной БК по сравнению со здоровыми и пациентами в стадии ремиссии [50]. Наблюдаемые изменения авторы связывают с усиленным митохондриальным бета-окислением, что предполагает высокую энергетическую потребность организма с болезнью Крона в привлечении иммунных клеток. У пациентов с активной стадией БК выявлены более значительные энергетические сдвиги, чем у лиц с БК в стадии ремиссии. При таком резком возрастании потребляемой энергии, вероятно, возникает воспалительная гипоксия, которая еще больше усиливает иммунную реакцию [51]. Интересно, что недавнее исследование метаболомики при ВЗК показало снижение окисления жирных кислот у пациентов с БК на фоне уменьшения как жирных кислот, так и ацилкарнитинов в крови, объяснение данного факта предполагает дальнейшие исследования [52].

Wiese DM и соавт. [28] показали меньшее содержание насыщенных жирных кислот и арахидоновой кислоты в сыворотке крови пациентов с ЯК, с более высокими уровнями мононенасыщенных, линолевой кислотой, олеиновой, эйкозапентаеновой и докозапентаеновой кислот. Авторы выявили прямые корреляции уровней ряда тканевых цитокинов (IL6, IL8, IL17, TNF-a, G-CSF) с насыщенными и обратные - с ненасыщенными, эйкозапентаеновой и докозапентаеновой ЖК у пациентов с ЯК, которые отсутствовали у здоровых лиц. Препараты 5-аминосалициловой кислоты снижали силу этих ассоциаций.

Одним из аспектов, который следует иметь в виду при анализе полученных результатов, является влияние проводимой терапии. Кроме препаратов 5-аминосалициловой кислоты, которые использовались в обеих группах пациентов с В3К, при обострении у ряда пациентов применялись кортикостероиды и иммуномодуляторы. Рассмотреть отдельно подгруппы с использованием разных методов терапии в данной работе не представлялось возможным в связи с малочисленностью групп и небольшим количеством «наивных» пациентов. Тем не менее, информация из ряда публикаций дает возможность сделать ряд предположений о возможном влиянии терапии. Данные Wiese DM и соавт. показали, что при использовании биологических препаратов, иммуномодуляторов или препаратов 5-АСК композиции жирных кислот сыворотки у пациентов с ЯК не различались [28]. Содержание ПНЖК оказалось выше у пациентов без терапии кортикостероидами, чем без них. В группах пациентов, находящихся на лечении стероидами или биологическими препаратами, не обнаруживалась связь между уровнями ЖК и провоспалительными цитокинами, что вероятно, связано с тем, что данные методы снижают влияние жирных кислот на воспалительный процесс. При использовании препаратов 5-АСК эти ассоциации ослабевали, но не исчезали, по сравнению с пациентами без терапии салицилатами. Это подтверждает взаимосвязь между метаболизмом жирных кислот до эйкозаноидов и воспалительным эффектом на ткани толстой кишки, что уже не проявляется при использовании ингибиторов синтеза эйкозаноидов (т.е., препаратов 5-АСК). Вероятно, у пациентов с более провоспалитель- 
ным профилем ЖК при ЯК следует использовать большие дозы препаратов 5-АСК.

Предыдущие исследования выявили более высокие уровни насыщенных и полиненасыщенных ЖК, а также арахидоновой, докозапентаеновой и докозагексаеновой в ткани толстой кишки пациентов с ЯК в стадии обострения по сравнению с ЯК в стадии ремиссии и у здоровых лиц $[53,54]$.

Следует заметить, что настоящее исследование имеет ряд ограничений. К ним стоит отнести небольшие группы пациентов с учетом вариабельности уровней жирных кислот в биологических образцах. Для более точной оценки состава и соотношения ЖК необходимо анализировать диетические жирнокислотные профили у пациентов.

С другой стороны, в настоящей работе были объединены пациенты с различными нозологическими формами заболевания - ЯК, БК и НКК. Вместе с тем, в предшествующем пилотном исследовании на небольших группах пациентов с ВЗК было нами показано наличие различий в уровнях ЖК в зависимости от варианта ВЗК [55], что подтверждается и другими авторами [56].

Наличие в настоящем исследовании данных, не согласующихся с результатами других работ, может быть обусловлено разным этническим, половозрастным составом групп пациентов, различиями по нозологическим формам ВЗК, проводимой терапии, использованием разных биологических образцов для анализа, особенностями пробоподготовки.

В настоящем исследовании мы попытались выявить общие черты «метаболического профиля» для обострения ВЗК и ремиссии, вне зависимости от нозологической формы. Можно предположить, что в дальнейшем при рассмотрении БК, ЯК, НКК отдельно с учетом стадии заболевания на больших когортах пациентов будут выявлены маркеры, ассоциированные с отдельными патологиями. Особенно перспективно направление, когда данные ЖК профилей сыворотки и мембран эритроцитов будут сопоставлены с «паттерном» ЖК тканей кишки пациентов с ВЗК.

\section{Зак^ючение}

Таким образом, исследование состава и соотношения жирных кислот в мембранах эритроцитов и сыворотке крови у пациентов с ВЗК в стадии обострения и ремиссии позволило сделать следующие выводы:

- у пациентов с ВЗК выявлено увеличение содержания насыщенных ЖК (преимущественно за счет пальмитиновой, стеариновой ЖК) в период обострения заболевания по сравнению со здоровы- ми лицами с последующим снижением при наступлении ремиссии;

- суммарное содержание ненасыщенных ЖК достоверно ниже у пациентов с ВЗК в стадии обострения по сравнению с группой контроля (в большей степени за счет мононенасыщенных, омега-6 полиненасыщенных жирных кислот) с увеличением процентного содержания у пациентов в неактивном статусе заболевания;

- соотношения насыщенные/ненасыщенные, насыщенные/полиненасыщенные, омега3/омега6 ПНЖК выше у пациентов с ВЗК в стадии обострения; отмечено снижение уровней соотношений у больных в стадии ремиссии;

- выявлены обратные корреляции суммарного содержания ненасыщенных, моно -, полиненасыщенных, омега-6 ПНЖК с маркерами воспаления; ассоциации суммарного содержания насыщенных ЖК и отдельных ЖК данного класса (пальмитиновой, стеариновой, арахиновой) оказались прямыми;

- при проведении анализа методами машинного обучения и ROC-анализа ключевыми биомаркерами для различения пациентов в стадии обострения от здоровых лиц оказались уровни следующих ЖК и их соотношения: E C18:2n-6, E C14:0/ S C14:0, E C17:0, E C20:0, E C16:1;7/ S C16:1;7, E C20:2n-6 / S C20:2n-6, E C16:1;9 / S C16:1;9, E C18:3n-3 / S C18:3n-3, E C16:1;9 (AUC0,962, чувствительность 0,939, специфичность 0,888, диагностическая точность - 0,919);

- для дифференцирования пациентов в стадии ремиссии от здоровых лиц - E C20:0, S C16:2n-6, E C16:1;9, E C18:0, E суммарное содержание насыщенных ЖК, Е С16:0,

- S суммарное содержание ненасыщенных ЖК, Е C18:3n-3 / S C18:3n-3 (AUC0,979, чувствительность 0,956, специфичность 0,962, диагностическая точность - 0,961);

- в различении стадий между собой - E C18:3n-3, S C12:0, S C16:1;9, E C20:4n-6, E C20:0, Е насыщ./ненасыщ./ S насыщ./ненасыщ., E C20:3n-6 /S C20:3n-6, Е C16:1;9, S C22:4n-6, Е омега 6/омега3 / S омега6/ омега3, E C18:2n-6 (АUC0,948, чувствительность 0,954, специфичность 1,0, диагностическая точность $-0,962)$.

Работа выполнена в рамках темы «Эпидемиологический мониторинг состояния здоровья населения и изучение молекулярно-генетических и молекулярно-биологических механизмов развития распространенных терапевтических заболеваний в Сибири для совершенствования подходов к их диагностике, профилактике и лечению» ГЗ № 0324-2018-0001, Рег. № АААА-A17-117112850280-2. 


\section{ЛИТЕРАТУРА}

1. Воспалительные заболевания кишечника. Клинические, эндоскопические, морфологические аспекты диагностики. Принципы современной терапии. / Головенко 0.В. [и др.].— М.: Прима Принт, 2017.— 180 c.: ил.—ISBN978-5-9907557-3-4.

2. Soubieres A.A., Poullis A. Emerging Biomarkers for the Diagnosis and Monitiring of Inflammatory Bowel Diseases. Inflamm. Bowel Dis. 2016, 22, 2016-2022.

3. «Клинические рекомендации «Язвенный колит» (утв. Минздравом России)// Российская гастроэнтерологическая ассоциация - Ассоциация колопроктологов России (год утверждения 2020) https://legalacts.ru/doc/klinicheskie-rekomendatsii-iazvennyi-kolit-utv-minzdravom-rossii/

4. Sandborn W.J., Feagan B.G., Hanauer S.B., Lochs H., et al. A review of activity indices and efficacy endpoints for clinical trials of medical therapy in adults with Crohn's disease. Gastroenterology 2002;122:512-30.

5. Travis S.P., Dinesen L. Remission in trials of ulcerative colitis: what does it mean? Pract Gastroenterol. 2010; 30: 17-20.

6. D"Haens G., et al. A review of activity indices and efficacy end points for clinical trials of medical therapy in adults with ulcerative colitis. Gastroenterology. 2007; 132: 763-86.

7. Reinisch W., Rutgeerts P., Panaccione R., D'Haens G., et al. Identifying appropriate dichotomizing points for SES-CD to predict long-term clinical remission for adalimumab-treated patients with Crohn's disease. J Crohns Colitis. 2010;4: P045.

8. Truelove S.C. et al. Cortisone in ulcerative colitis; final report on a therapeutic trial. Br Med J. 1955; 2: 1041-8.

9. Schroeder K.W., Tremaine W.J., Ilstrup D.M. Coated oral 5-aminosalicylic acid therapy for mildly to moderately active ulcerative colitis. A randomized study. N Engl J Med. 1987; 317: 1625-9.

10. Geboes K., Riddel R., Jensfelt B., et al. A reproducible grading scale for histological assessment of inflammation in ulcerative colitis. Gut 2000; 47: 404409

11. Белоусова Е.А. Рекомендации по диагностике и лечению болезни Крона. Фарматека. 2009; № 13, c. 38-44.

12. Torres J., Bonovas S., Doherty G., Kucharzik T., et al. ECCO Guidelines on Therapeutics in Crohn's Disease: Medical Treatment. Journal of Crohn's and Colitis. 2020; 4(1): $4-22$.

13. BestW.R., Becktel J.M., Singleton J.W., Kern F. Jr. Development of a Crohn's disease activity index. National Cooperative Crohn's Disease Study. Gastroenterology. 1976 Mar;70(3):439-44.

14. Mary J.Y., Modigliani R. Development and validation of an endoscopic index of the severity for Crohn, $s$ disease: a prospective multicentre study. Groupe $d$, Etudes Therapeutiques des Affections Inflammatores du Tube Digestif (GETAID). Gut 1989; 30(7): 983-9.

15. Клинические рекомендации по диагностике и лечению болезни Крона у взрослых (Проект). Колопроктология, том 19, № 2, 2020, c. 8-38 https://doi. org/10.33878/2073-7556-2020-19-2-8-38

16. Panes J., Jairath V., Levesque B.G. Advances in Use of Endoscopy, Radiology, and Biomarkers to Monitor Inflammatory Bowel Diseases. Gastroenterology. 2017 Feb;152(2):362-373.e3. doi: 10.1053/j.gastro.2016.10.005. Epub 2016 0ct 15. PMID: 27751880.

17. Madsen R.; Lundstedt T.; Trygg J. Chemometrics in metabolomic — A review in human disease diagnosis. Anal. Chim. Acta 2010, 659, 23-33.

18. Williams H.R.; Willsmore J.D.; Cox I.J.; Walker D.G.; Cobbold J.F;; Taylor-Robinson S.D.; Orchard T.R. Serum metabolic profiling in inflammatory bowel disease. Dig. Dis. Sci. 2012, 57, 2157-2165.

19. Murdoch T.B.; Fu H.; MacFariane S.; Sydora B.C.; Fedorak R.N.; Slupsky C.M. Urinary metabolic profiles of inflammatory bowel disease in interleukin-10 gene-deficient mice. Anal. Chem. 2008, 80, 5524-5531.

20. Bezabeh T.; Somorjai R.L.; Smith I.C. MR metabolomics of fecal extracts: Applications in the study of bowel diseases. Magn. Reson. Chem. 2009, 47 (Suppl. 1), S54-S61.

21. Pan Z.; Raftery D. Comparing and combining NMR spectroscopy and mass spectrometry in metabolomics. Anal. Bioanal. Chem. 2007, 387, 525-527.

22. Kolho K.L.; Pessia A.; Jaakkola T.; de Vos W.M.; Velagapudi V. Faecal and Serum Metabolomics in Paediatric Inflammatory Bowel Disease. J. Crohns Colitis 2017, 11, 321-334.

23. Scoville E.A.; Allaman M.M.; Brown C.T.; Motley A.K.; Horst S.N.; Williams C.S.; Koyama T.; Zhao Z.; Adams D.W.; Beaulieu D.B.; et al. Alterations in Lipid, Amino Acid, and Energy Metabolism Distinguish Crohn's Disease from Ulcerative Colitis and Control Subjects by Serum Metabolomic Profiling. Metabolomics 2018, $14,17$.

24. Кручинина М.В., Кручинин В.Н., Прудникова Я.И., Громов А.А., Шашков М.В., Соколова А.С. Исследование уровня жирных кислот мембран эритроцитов и сыворотки крови у пациентов с колоректальным раком г. Новосибирска // Успехи молекулярной онкологии. — 2018. - T. 5. - № 2. - С. 50-61.

25. https://h20-release.s3.amazonaws.com/h20/rel-zermelo/4/docs-website/h20-docs/variable-importance.html\#variable-importance-calculation-gbm-drf

26. Seimon T.A., Nadolski M.J., Liao X., Magallon J., et al. Atherogenic lipids and lipoproteins trigger CD36-TLR2-dependent apoptosis in macrophages undergoing endoplasmic reticulum stress // Cell Metab. - 2010. — Vol. 12. - P. 467-482.

27. Saraswathi V., Hasty A.H. Inhibition of long-chain acyl coenzyme A synthetases during fatty acid loading induces lipotoxicity in macrophages // Arterioscler. Thromb. Vasc. Biol.—2009. — Vol. 29. - P. 1937-1943.

28. Wiese D.M., Horst S.N., Brown C.T., Allaman M.M., Hodges M.E., Slaughter J.C., Druce J.P., Beaulieu D.B., Schwartz D.A., Wilson K.T., Coburn L.A. Serum Fatty Acids Are Correlated with Inflammatory Cytokines in Ulcerative Colitis. PLoS One. 2016 May 26;11(5): e0156387. doi: 10.1371/journal.pone.0156387. PMID: 27227540. PMCID: PMC4882051.

29. Таганович А.Д., Олецкий Э.И., Котович И.Л. Патологическая биохимия / Под общ. ред. А.Д. Тагановича — М.: Изд-во БИНОМ, 2013, 448 с.

30. Fritz V., Benfodda Z., Rodier G., Henriquet C., et al. Abrogation of de novo lipogenesis by stearoyl-CoA desaturase 1 inhibition interferes with oncogenic signaling and blocks prostate cancer progression in mice // Mol. Cancer Ther. - 2010. - Vol. 9. - P. 1740-54.

31. Stillwell W. An introduction to biological membtanes. Composition, structure and function. Second edition. UK London: Elsevier, 2016, $432 \mathrm{p}$. 
32. Hodson L., Skeaff C.M., Fielding B.A. Fatty acid composition of adipose tissue and blood in humans and its use as a biomarker of dietary intake // Prog. Lipid. Res. 2008. - Vol. 47. - P. 348-380.

33. Asciutti-Moura L.S., Guilland J.C., Fuchs F., Richard D., Klepping J. Fatty acid composition of serum lipids and its relation to diet in an elderly institutionalized population // Am.J. Clin. Nutr. - 1988. Vol. 48. - P. 980-987.

34. Uchiyama K., Odahara S., Nakamura M., Koido S., Katahira K., Shiraishi H., Ohkusa T., Fujise K., Tajiri H. The fatty acid profile of the erythrocyte membrane in initialonset inflammatory bowel disease patients // Dig. Dis. Sci. - 2013. - Vol. 58. -P. 1235-1243.

35. Shoda R., Matsueda K., Yamato S., Umeda N. Epidemiologic analysis of Crohn disease in Japan: increased dietary intake of n- 6 polyunsaturated fatty acids and animal protein relates to the increased incidence of Crohn disease in Japan. // Am.J. Clin. Nutr. 1996. Vol. 63. No. 5. P. 741-5.

36. Friedman A.N., Yu Z., Tabbey R., Denski C., Tamez H., Wenger J., Thadhani R.Y., Watkins B.A. Low blood levels of long-chain n-3 polyunsaturated fatty acids in US hemodialysis patients: clinical implications // Am.J. Nephrol. 2012. Vol. 36. P. 451-458.

37. Novak T.E., Babcock T.A., Jho D.H., Helton W.S., Espat N.J. NF-kappa B inhibition by Omega -3 fatty acids modulates LPS-stimulated macrophage TNF-alpha transcription // Am.J. Physiol. Lung Cell Mol. Physiol. 2003. Vol. 284. P. L84-L89.

38. Belluzzi A., Boschi S., Brignola C., Munarini A., Cariani G., Miglio F. Polyunsaturated fatty acids and inflammatory bowel disease // Am.J. Clin. Nutr. 2000. Vol. 71. No. 1. P. 339S-342S.

39. Sharon P., Stenson W.F. Enhanced synthesis of leukotriene B4 by colonic mucosa in inflammatory bowel disease // Gastroenterology. 1984. Vol. 86. No. 3. P. 453-60.

40. Marion-Letellier R., Savoye G., Beck P.L., Panaccione R., Ghosh S. Polyunsaturated fatty acids in inflammatory bowel diseases: a reappraisal of effects and therapeutic approaches // Inflamm. Bowel Dis. 2013. Vol. 19. No. 3. P. 650-61.

41. Li Q, Zhang Q, Wang M, Zhao S, Xu G, Li J. n-3 polyunsaturated fatty acids prevent disruption of epithelial barrier function induced by proinflammatory cytokines. Mol Immunol. 2008 Mar;45(5):1356-65. doi: 10.1016/j.molimm.2007.09.003.

42. Masoodi M., Pearl D.S., Eiden M., Shute J.K., Brown J.F., Calder P.C., Trebble T.M. Altered colonic mucosal Polyunsaturated Fatty Acid (PUFA) derived lipid mediators in ulcerative colitis: new insight into relationship with disease activity and pathophysiology // PloS One. 2013. Vol. 8. No. 10. P. e76532-7.

43. Yessoufou A., Ple A., Moutairou K., Hichami A. and Khan N.A. Docosahexaenoic acid reduces suppressive and migratory functions of CD4+CD25+ regulatory T-cells. J Lipid Res 2009; 50: 2377-2388

44. Woodworth H.L., McCaskey S.J., Duriancik D.M., Clinthorne J.F., Langohr I.M., Gardner E.M. and Fenton J.I. Dietary fish oil alters T lymphocyte cell populations and exacerbates disease in a mouse model of inflammatory colitis. Cancer Res 2010; 70: 7960-796.

45. Nishiumi S.; Izumi Y.; Yoshida M. Alterations in Docosahexaenoic Acid-Related Lipid Cascades in Inflammatory Bowel Disease Model Mice. Digestive Dis. Sci. 2018, 63, 1485-1496.

46. Cabre E.; Manosa M.; Gassull M.A. Omega-3 fatty acids and inflammatory bowel diseases — A systematic review. Br.J. Nutr. 2012, 107 (Suppl. 2), S240-S252.

47. Tabbaa M.; Golubic M.; Roizen M.; Bernstein A. Docosahexaenoic Acid, Inflammation, and Bacterial Dysbiosis in Relation to Periodontal Disease, Inflammatory Bowel Disease, and the Metabolic Syndrome. Nutrients 2013, 5, 3299-3310.

48. Okuyama H., Kobayashi T., Watanabe S. Dietary fatty acids — The n-6/n-3 balance and chronic elderly disease // Prog. Lipid Res. — 1997. — Vol. 35.—P. 409-457.

49. Asciutti-Moura L.S., Guilland J.C., Fuchs F., Richard D., Klepping J. Fatty acid composition of serum lipids and its relation to diet in an elderly institutionalized population // Am.J. Clin. Nutr. — 1988. Vol. 48.—P. 980-987.

50. Lai Y, Xue J, Liu CW, Gao B, Chi L, Tu P, Lu K, Ru H. Serum Metabolomics Identifies Altered Bioenergetics, Signaling Cascades in Parallel with Exposome Markers in Crohn's Disease. Molecules. 2019 Jan 27;24(3):449. doi: 10.3390/molecules24030449. PMID: 30691236; PMCID: PMC6385106.

51. Lu K.; Knutson C.G.; Wishnok J.S.; Fox J.G.; Tannenbaum S.R. Serum metabolomics in a Helicobacter hepaticus mouse model of inflammatory bowel disease reveal important changes in the microbiome, serum peptides, and intermediary metabolism. J. Proteome Res. 2012, 11, 4916-4926.

52. Scoville E.A.; Allaman M.M.; Brown C.T.; Motley A.K.; Horst S.N.; Williams C.S.; Koyama T.; Zhao Z.; Adams D.W.; Beaulieu D.B.; et al. Alterations in Lipid, Amino Acid, and Energy Metabolism Distinguish Crohn's Disease from Ulcerative Colitis and Control Subjects by Serum Metabolomic Profiling. Metabolomics 2018, $14,17$.

53. Fernandez-Banares F., Esteve-Comas M., Mane J., Navarro E., Bertran X., Cabre E., et al. Changes in mucosal fatty acid profile in inflammatorybowel disease and in experimental colitis: a common response to bowel inflammation. Clin Nutr. 1997;16(4):177-83. Epub 1997/08/01. S0261-5614(97)80003-9

54. Pearl D.S., Masoodi M., Eiden M., Brümmer J., Gullick D., McKeever T.M., et al. Altered colonic mucosal availability of n-3 and n-6 polyunsaturated fatty acids in ulcerative colitis and the relationship to disease activity. J Crohns Colitis. 2014;8(1):70-9. doi: 10.1016/j.crohns.2013.03.013

55. Кручинина М.В., Азгалдян А.В., Светлова И.О., Шашков М.В., Соколова А.С., Кручинин В.Н. Особенности состава жирных кислот сыворотки крови и мембран эритроцитов у пациентов с воспалительными заболеваниями кишечника (пилотное исследование) // Современные проблемы науки и образования.—2019.— № 3. http://www.science-education.ru/ru/article/ view?id=28868 (дата обращения: 10.06.2019). D0l: 10.17513/spno.28868.

56. Uchiyama K., Odahara S., Nakamura M., Koido S., Katahira K., Shiraishi H., Ohkusa T., Fujise K., Tajiri H. The fatty acid profile of the erythrocyte membrane in initialonset inflammatory bowel disease patients // Dig. Dis. Sci._ 2013. - Vol. 58. -P. 1235-1243.

( Кручинина Маргарита Витальевна ( kruchmargo@yandex.ru ), Светлова Ирина Олеговна,

Азгалдян Александра Викторовна ( communis2016@gmail.com ), Осипенко Марина Федоровна ( ngma@bk.ru ),

Валуйских Екатерина Юрьевна ( valuyskich@mail.ru ), Шашков Михаил Вадимович ( misha_chem@ngs.ru ),

Соколова Анастасия Сергеевна ( a.s_sokolova@mail.ru ), Кручинин Владимир Николаевич ( vladd.kruch@yandex.ru ),

Яковина Ирина Николаевна ( irina.nir@gmail.com ), Осипенко Иван Викторович ( taur.os.iv@gmail.com ).

Журнал «Современная наука: актуальные проблемы теории и практики» 